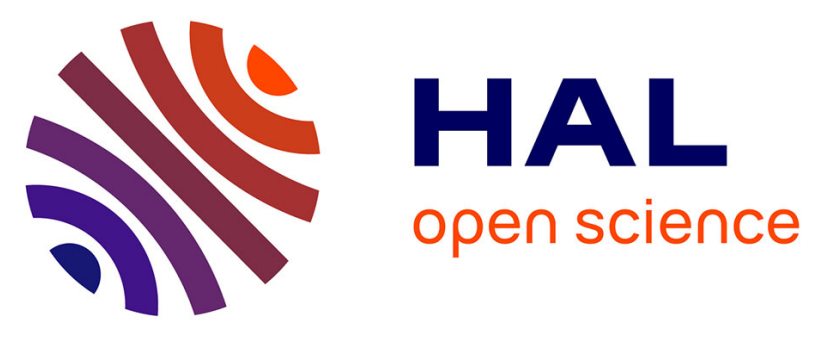

\title{
Experimental and theoretical study of tracer diffusion in a series of (CoCrFeMn) 100-xNi alloys
}

\author{
Josua Kottke, Daniel Utt, Mathilde Laurent-Brocq, Adnan Fareed, Daniel \\ Gaertner, Loic Perriere, Łukasz Rogal, Alexander Stukowski, Karsten Albe, \\ Sergiy V Divinski, et al.
}

\section{To cite this version:}

Josua Kottke, Daniel Utt, Mathilde Laurent-Brocq, Adnan Fareed, Daniel Gaertner, et al.. Experimental and theoretical study of tracer diffusion in a series of (CoCrFeMn) $100-x N i$ alloys. Acta Materialia, 2020, 194, pp.236 - 248. 10.1016/j.actamat.2020.05.037 . hal-03045529

\author{
HAL Id: hal-03045529 \\ https://hal.science/hal-03045529
}

Submitted on 15 Dec 2020

HAL is a multi-disciplinary open access archive for the deposit and dissemination of scientific research documents, whether they are published or not. The documents may come from teaching and research institutions in France or abroad, or from public or private research centers.
L'archive ouverte pluridisciplinaire $\mathbf{H A L}$, est destinée au dépôt et à la diffusion de documents scientifiques de niveau recherche, publiés ou non, émanant des établissements d'enseignement et de recherche français ou étrangers, des laboratoires publics ou privés. 
Kottke, J., Utt, D., Laurent-Brocq, M., Fareed, A., Gaertner, D., Perrière, L., Rogal, Ł., Stukowski, A., Albe, K., Divinski, S.V., and Wilde, G., Acta Materialia, 2020. 194: p. 236-248

https://doi.org/10.1016/j.actamat.2020.05.037

\title{
Experimental and theoretical study of tracer diffusion in a series of $(\mathrm{CoCrFeMn})_{100-x} \mathrm{Ni}_{x}$ alloys
}

\author{
Josua Kottke ${ }^{\mathrm{a}, *}$, Daniel Utt ${ }^{\mathrm{b}, *}$, Mathilde Laurent-Brocq ${ }^{\mathrm{c}}$, Adnan Fareed ${ }^{\mathrm{a}}$, Daniel Gaertner ${ }^{\mathrm{a}}$, Loïc Perrière ${ }^{\mathrm{c}}$, Łukasz \\ Rogal $^{\mathrm{d}}$, Alexander Stukowski ${ }^{\mathrm{b}}$, Karsten Albe ${ }^{\mathrm{b}}$, Sergiy V. Divinski ${ }^{\mathrm{a}}$, Gerhard Wilde ${ }^{\mathrm{a}}$ \\ ${ }^{a}$ Institute of Materials Physics, University of Münster, 48149 Münster, Germany \\ ${ }^{b}$ Fachgebiet Materialmodellierung, Institut für Materialwissenschaft, TU Darmstadt, 64287 Darmstadt, Germany \\ ${ }^{c}$ Université Paris-Est Créteil, CNRS, ICMPE (UMR 7182), 2 rue Henri Dunant, 94320 Thiais, France \\ ${ }^{d}$ Institute of Metallurgy and Materials Science of the Polish Academy of Sciences, 30-059 Krakow, Poland
}

\begin{abstract}
Tracer diffusion of all constituting elements is studied at various temperatures in a series of $(\mathrm{CoCrFeMn})_{100-x} \mathrm{Ni}_{x}$ alloys with compositions ranging from pure $\mathrm{Ni}$ to the equiatomic $\mathrm{CoCrFeMnNi}$ high-entropy alloy. At a given homologous temperature, the measured tracer diffusion coefficients change non-monotonically along the transition from pure $\mathrm{Ni}$ to the concentrated alloys and finally to the equiatomic $\mathrm{CoCrFeMnNi}$ alloy. This is explained by atomistic MonteCarlo simulations based on a modified embedded-atom potentials, which reveal that local heterogeneities of the atomic configurations around a vacancy cause correlation effects and induce significant deviations from predictions of the random alloy model.
\end{abstract}

Keywords: high entropy alloy; diffusion; bulk diffusion; KMC; Random alloy model; Tracer diffusion measurement;

\section{Introduction}

Traditionally, alloys have been developed according to a 'base element' paradigm, where one element of the alloy is predominant, e.g. nickel in super alloys or simply iron ${ }_{30}$ 5 in steel, and other elements are taken to improve their properties [1]. Since 2004, a new concept, proposed by Yeh et al.. [2] and Cantor et al. [3], has gained greater attention, and alloys with multiple principal elements have been investigated. The concentration of each element in 10 these alloys varies between 5 and 35 at.\% but still forms a solid solution. These alloys are commonly known as multiprincipal-element alloys or further as high-entropy alloys (HEAs) [4]. The last name goes back to Yeh et al. [2] because the sheer amount of different elements significantly 15 increases the entropy of mixing $\Delta S_{m i x}$. Some of these HEAs have exhibited very promising mechanical properties $[5,6]$, thus initiating a very dynamic field of research. Step by step, properties of HEAs are explored and one of primary importance is diffusion and the activation barriers ${ }_{45}$ 20 for kinetic processes.

A concept of 'sluggish' diffusion in HEAs in comparison to conventional alloys was proposed as one of the four 'core effects' of HEAs [7]. The first interdiffusion measurements of the $\mathrm{CoCrFeMn}{ }_{0.5} \mathrm{Ni}$ alloys seemed to support this ${ }_{50}$ paradigm [8]. Nowadays, the concept of 'sluggish' diffusion

\footnotetext{
* Corresponding author

Email addresses: josua.kottke@uni-muenster.de (Josua Kottke), utt@mm.tu-darmstadt.de (Daniel Utt)
}

has been questioned $[9,10,11,4,12]$. Moreover, the latest diffusion measurements on HEAs have shown that the determination whether diffusion in HEAs is sluggish or not is not straightforward [13] and highly debated [14, 15]. In fact, the type of elements which are involved in the alloy seems to play a more important role than the configurational entropy [16]. For recent reviews of the available diffusion data in HEAs see, e.g. [12, 17, 18].

Due to the high configuration complexity of HEAs atomistic computational studies of diffusion in the concentrated solid solutions are rare $[12,19,20]$ and mostly focus on the equimolar Cantor alloy. Choi et al. [19] sampled the vacancy migration energy for 390 vacancy jumps in the equimolar Cantor alloy using their recently developed empirical interatomic potential. They report a broad distribution of migration barriers with a maximum between $0.67 \mathrm{eV}$ to $0.87 \mathrm{eV}$ and vacancy formation energies in the range of $0.694 \mathrm{eV}$ to $1.207 \mathrm{eV}$. The calculated hierarchy of migration barriers for different diffusing elements closely matches the experimental diffusivities reported by Tsai et al. [8]. Therefore, these authors conclude, that the broad energy distribution can lead to chemical environments in the HEA where the vacancy gets trapped, which would in turn reduce the vacancy diffusivity and support claims of sluggish diffusion.

Vacany migration and formation energies were also studied by Mizuno et al. [20] based on caclulations within electronic density functional theory (DFT). They calculated the vacancy migration energies for each element in 6 differ55 ent chemical environments using DFT and the previously 
mentioned interatomic potential and found good agreement between both methods. Contrary to the classical model by Choi et al. [19] the average vacancy formation ${ }_{115}$ energies calculated by DFT are almost identical for all elements ranging from 1.93 to $2.06 \mathrm{eV}$. However, neither the interatomic potential calculations [19] nor the DFT calculations [20] are in line with the vacancy formation enthalpy in the Cantor alloy measured by positron annihilation spectroscopy of $1.69(13) \mathrm{eV}, 1.72(18) \mathrm{eV}$ [21], or $650.64 \mathrm{eV}[22]$.

In order to obtain a complete understanding of diffusional transport in solids, statistical Monte Carlo (MC) simulations, which can trace many elementary vacancy jumps, are a powerful tool. In the context of high en70 tropy alloys, the random alloy model has been used by ${ }_{125}$ Belova et al. [23, 24] assuming that species and vacancies are randomly distributed, which implies that average values can be used to represent the actual atom and vacancy jump frequencies in the lattice [25]. The results of such simulations can express experimentally measurable ${ }_{130}$ tracer diffusion coefficients which especially allows direct comparison with experiments. However, the random alloy model neglects explicitly the environmental dependence of the jump frequencies and the introduced errors have to be estimated yet.

In the present paper, we have combined tracer diffusion measurements and a novel type of Monte-Carlo simulations, in order to clarify the 'sluggish diffusion' core effect and to understand kinetic processes in HEAs. In doing so, we study diffusion rates of elements in multi-component ${ }_{140}$ alloys within the Cantor system for compositions varied from a pure metal to a concentrated solid solution and finally to a HEA, following the approach developed earlier by Laurent-Brocq et al. to study the thermodynamic 90 stability [26] and the solid solution strengthening [27, 28].145 Thus, the influence of the concentration of each element on diffusion in HEAs can be determined without having to take into account the influence of the chemical nature of the elements. The present investigation extends the previous experimental study of tracer diffusion in the $\mathrm{Ni}_{-150}$ CoCrFeMn alloys [29] which was conducted at a single temperature of $1373 \mathrm{~K}$.

The tracer diffusion of all constituting elements is measured in $\mathrm{Co}_{10} \mathrm{Cr}_{10} \mathrm{Fe}_{10} \mathrm{Mn}_{10} \mathrm{Ni}_{60}$ and $\mathrm{Co}_{2} \mathrm{Cr}_{2} \mathrm{Fe}_{2} \mathrm{Mn}_{2} \mathrm{Ni}_{92}$ sults are compared to already existing diffusion data for $\mathrm{Co}_{20} \mathrm{Cr}_{20} \mathrm{Fe}_{20} \mathrm{Mn}_{20} \mathrm{Ni}_{20}$ and pure nickel. In order to complete the diffusion databases, we measured Mn diffusion in pure $\mathrm{Ni}$, too. Thus, diffusion in a series of ${ }_{105}(\mathrm{CoCrFeMn})_{100-x} \mathrm{Ni}_{x}$ alloys is evaluated $(20 \leq x \leq 100){ }_{.160}$ All chosen materials were already proven to form single face-centered cubic (FCC) solid solutions [26, 30, 27]. To improve the understanding of the obtained trends in the diffusion constants, atomistic computer simulations are performed, sampling the concentration and chemical en-165 vironment specific vacancy migration barrier in the Cantor subsystems. These barriers are used as an input for a novel, custom-built kinetic Monte Carlo code. The diffusion constants determined from this code are compared to the experimental results. Moreover, the impact of the migration barrier distribution on the tracer correlation factors is determined comparing the results of our KMC code to the ones determined from the established random alloy model.

\section{Experimental details}

The $\mathrm{Co}_{10} \mathrm{Cr}_{10} \mathrm{Fe}_{10} \mathrm{Mn}_{10} \mathrm{Ni}_{60}$ and $\mathrm{Co}_{2} \mathrm{Cr}_{2} \mathrm{Fe}_{2} \mathrm{Mn}_{2} \mathrm{Ni}_{92}$ alloys were cast by high frequency electromagnetic induction melting in a water-cooled copper crucible under $\mathrm{He}$ atmosphere. $\mathrm{Co}, \mathrm{Cr}, \mathrm{Fe}, \mathrm{Mn}$ and $\mathrm{Ni}$ metal pieces of at least $99.95 \%$ purity were melted together and suctioncast as rod-shaped ingots with a diameter of $13 \mathrm{~mm}$. Subsequently, the rods were wrapped in Ta foil, annealed at $1373 \mathrm{~K}$ for $13 \mathrm{~h}$ under a He atmosphere for chemical homogenization and rapidly quenched afterwards. The chemical composition was examined by energy dispersive X-ray spectroscopy (EDS, Merlin Zeiss Field Emission Scanning Electron Microscope with detectors from Oxford Instruments) at several positions. The determined averaged concentrations are summarized in Appendix, Table A.4.

After homogenization, the $\mathrm{Co}_{10} \mathrm{Cr}_{10} \mathrm{Fe}_{10} \mathrm{Mn}_{10} \mathrm{Ni}_{60}$ and $\mathrm{Co}_{2} \mathrm{Cr}_{2} \mathrm{Fe}_{2} \mathrm{Mn}_{2} \mathrm{Ni}_{92}$ samples were cut by spark erosion and pre-annealed at the diffusion temperatures (wrapped in $\mathrm{Ta}$ foil and sealed in quartz ampules under purified Ar atmosphere) to ensure thermal equilibrium conditions. A further set of sample was annealed at $1173 \mathrm{~K}$ for $\mathrm{X}$ ray examination. A single face-centred cubic phase at all temperatures was confirmed by X-ray diffraction (XRD) (see Fig. A.8 in Appendix).

The microstructure was examined using a FEI Nova NanoSEM 230 scanning electron microscope (SEM) performing electron back-scatter diffraction (EBSD) analysis. Similar coarse-grained FCC structures were found for both, $\mathrm{Co}_{10} \mathrm{Cr}_{10} \mathrm{Fe}_{10} \mathrm{Mn}_{10} \mathrm{Ni}_{60}$ and $\mathrm{Co}_{2} \mathrm{Cr}_{2} \mathrm{Fe}_{2} \mathrm{Mn}_{2} \mathrm{Ni}_{92}$ alloys. The majority of identified grains featured sizes larger than $100 \mu \mathrm{m}$, in agreement with the measurements of Laurent-Brocq et al. [27, 31] (see in particular Appendix B in [27] and Table 1 in [31]). Only small precipitations, several micrometer large, were occasionally observed. For both alloys, the textures turned out to be close to random without any preferential orientation of the grains.

The impact of alloying and plastic deformation on the microstructure in these high-entropy alloys is analyzed in detail in Refs. [27, 28]. Further details could be found in corresponding reviews, see e.g. Refs. [4, 32].

A few microliters of a mixture of $\gamma$-isotopes, i.e. of ${ }^{51} \mathrm{Cr},{ }^{54} \mathrm{Mn},{ }^{57} \mathrm{Co}$ and ${ }^{59} \mathrm{Fe}$, were dropped on a mirror-like polished surface of the samples. A second set of identical samples was used for diffusion experiments with the ${ }^{63} \mathrm{Ni} \beta$-isotope. Both sets were diffusion annealed at the selected temperatures for given times (see the experimental conditions listed in Table 1). Afterwards, the spec- 
imens were reduced in diameter to exclude an influence of surface and lateral diffusion. The penetration profiles were determined measuring the relative specific activity of successive sections, which were parallel-sectioned using a custom-built precise mechanical grinding machine. The thickness of each section was determined from the sample 220 mass difference before and after each grinding step.

Diffusion on ${ }^{54} \mathrm{Mn}$ in pure Ni was measured in a similar way.

\section{Details of atomistic calculations}

\subsection{Nudged elastic band calculations}

The nudged elastic band (NEB) method [33, 34] is used to determine the vacancy migration energy in the different ${ }^{225}$ Cantor alloy subsystems. For each (CoCrFeMn) ${ }_{100-x} \mathrm{Ni}_{x}$ sample with $x=20,60,80$ and 92 a FCC single crystal containing 4000 lattice sites is created. The different species are distributed randomly on these sites. The single crystalline samples are first statically relaxed to zero pressure with a maximum force tolerance of $10^{-8} \mathrm{eV} \AA^{-1}$ using conjugate gradient energy minimization. For the following NEB calculations, initial, intermediate, and final states are minimized at constant volume to an energy tol- ${ }_{230}$ a large number of chemical environments around the vacancy and the migrating atom we now iteratively remove one atom from the sample and calculate the migration barrier for all neighboring atoms jumping in the created $_{235}$ the removed atom is reinserted and a different atom in the sample is removed. This process is repeated until all lattice sites have hosted the vacancy. Forward and backwards jumps are not calculated twice as they have symmetrical $_{240}$ migration energy barriers.

For these calculations LAMMPS is used [36]. The atomic interactions are described by an empirical second nearest neighbor modified embedded atom interatomic potential parametrized by Choi et al. [19]. All samples are created $_{24}$ is done in OVITO [38].

\subsection{Kinetic Monte Carlo simulations}

For this study we developed a novel rejection-free ki-250 netic Monte-Carlo [39] code, where migration energies are ndividually picked from a calculated gaussian distribution. It is assumed that this distribution of migration barriers depends solely on the type of the migrating atom and the overall sample composition ( $c f$. Fig. 4). The barriers255 used are given in Tab. 3. Each KMC step consists of the following operations [40]:

1. Determine the atomic species in the first nearest neighbor shell of the vacancy.

2. For each neighbor a migration energy $\Delta E_{i}$ is drawn from its respective distribution of migration energies.
3. Calculate the rate $\Gamma_{i}$ for each neighbor exchanging site with the vacancy following

$$
\Gamma_{i}=\nu_{0} \exp \left(-\frac{\Delta E_{i}}{k_{\mathrm{B}} T}\right)
$$

where $\nu_{0}=10^{13} \mathrm{~s}^{-1}$ is the attempt frequency, $k_{\mathrm{B}}$ is the Boltmzann constant, $T$ is the temperature.

4. The total rate $\Gamma_{\text {tot }}$ is equal to

$$
\Gamma_{\mathrm{tot}}=\sum_{i} \Gamma_{i}
$$

5. A random number $u \in(0,1]$ is drawn and an event is selected from the rate catalog so that $\Gamma_{i-1}<u \Gamma_{\text {tot }} \leq$ $\Gamma_{i}$.

6. The event is applied to the system, i.e. the selected atom is exchanged with the vacancy resulting in a diffusive jump.

7. A second random number $u^{\prime}$ is drawn and the time $t$ is advanced by $\Delta t$,

$$
\Delta t=\frac{1}{\Gamma_{\text {tot }}} \ln \left(1 / u^{\prime}\right) .
$$

Figure 1 shows an example for the migration barrier $\Delta E$ distribution for three species (a) and a schematic of a $\mathrm{KMC}$ step (b-c). In (b) each neighbor of the vacancy ' $\mathrm{V}$ ' gets assigned a migration energy drawn from the distribution. Going from (b) to (c) an event is selected and carried out, the clock is advanced by $\Delta t$. Now, each neighbor around the vacancy position receives a different energy barrier which is drawn from the energy distribution. These steps are repeated $10^{8}$ times and we obtain the trajectories for atoms and the vacancy, as well as the simulated time.

As this modelling approach does not account for the site-specific local chemical environments but only for a statistically correct distribution of all possible environments, the detailed balance criterion is not fulfilled for the individual jumps. Nevertheless, a large number of jumps leads the system towards a global equilibrium.

All following KMC results are obtained from a sample containing 32000 lattice sites with a single vacancy. These lattice sites are randomly filled with atoms in the desired concentration. Periodic boundary conditions are employed to approximate an infinitely large sample.

Using a single valued energy barrier distribution in this KMC code gives identical properties as the conventional random alloy model. We used this setup as a benchmark and compared the correlation factors obtained from the newly developed code after $10^{6}$ and $10^{8}$ simulation steps to the $f$ values calculated from a conventional random alloy model after $10^{12}$ steps. The results of this comparsion are shown in Fig. A.9 in the Appendix

The tracer correlation factor, $f$, influences the tracer diffusion coefficient, $D^{*}$,

$$
\begin{aligned}
D^{*} & =f D, \\
D & =c_{\mathrm{Vac}} \nu_{0} \lambda^{2} \exp \left(\frac{-\Delta E_{\mathrm{Mig}}}{k_{\mathrm{B}}, T}\right)
\end{aligned}
$$



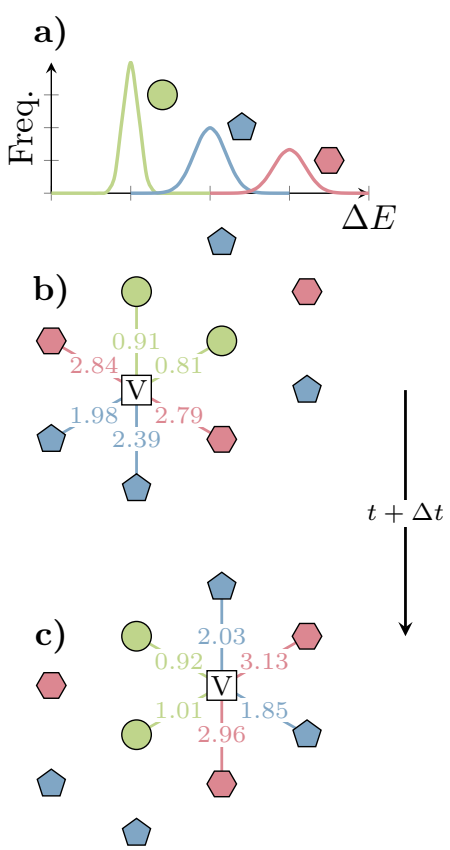

Figure 1: Exemplary migration energy barrier distribution in (a) showing three different species with different mean barriers and standard deviation. $\Delta E$ is the migration barrier and Freq. denotes the frequency for each energy occurring. During each KMC step each neighbor of the vacancy ' $\mathrm{V}$ ' is assigned a migration energy drawn from the distribution (a). A migration event is select based on the ${ }^{290}$ rejection free KMC formalism, the event is carried out and the clock is advanced $(\mathrm{b} \rightarrow \mathrm{c})$. The energy assignment is repeated for the next KMC step (c). The numbers in (b) and (c) represent the particular values of the migration barriers for possible vacancy jumps.

where $D$ is the bulk diffusivity and $c_{\text {Vac }}$ is the vacancy concentration [41]. The correlation factor can be obtained from KMC simulations by counting the number of jumps $n_{i}$ and the displacement $R_{i}$ of each atom $i . f$ is given then as,

$$
f=\frac{\sum_{i} R_{i}^{2}}{\sum_{i} n_{i} \lambda^{2}},
$$

where $\lambda$ is the jump length of a diffusional jump [42].

\section{Results and discussion}

\subsection{Volume diffusion}

In this study, we focus on volume diffusion even though short-circuit diffusion paths were occasionally also observed. The experimental conditions (temperatures $T$ and times ${ }_{310}$ $t$ ) of the diffusion experiments are summarized in Table 1. Examples of the measured concentration profiles are shown in Fig. 2, where the penetration profiles of all constituting elements in $\mathrm{Co}_{10} \mathrm{Cr}_{10} \mathrm{Fe}_{10} \mathrm{Mn}_{10} \mathrm{Ni}_{60}$ at $1123 \mathrm{~K}$ are presented. Two contributions, representing volume and grain $_{315}$ boundary diffusion at near-surface and deeper depths, respectively, can clearly be distinguished in this particular

The volume diffusion coefficients can be extracted by plotting the logarithm of the relative specific activity, $A$, of the tracer against the diffusion depth squared, $y^{2}$. In this representation, a linear decrease of the tracer concentration is observable up to a certain depth, depending on the diffusion temperature and the annealing time. For the analysis, the instantaneous source solution of the diffusion problem is used [43],

$$
A(y, t)=\frac{M}{\sqrt{4 \pi D^{*} t}} \exp \left(-\frac{y^{2}}{4 D^{*} t}\right) .
$$

Here, $M$ is the initial amount of tracer applied onto the surface and $t$ is the diffusion annealing time. Consequently, the volume diffusion coefficients, $D_{i}^{*}$, of each tracer $i$ can directly be determined by fitting the relevant parts of the penetration profiles according to Eq. (7). Such contributions are seen, e.g., in Fig. 2 till the depths of about $20 \mu \mathrm{m}$.

In some cases of tracer deposition, an increased amount of the remnant tracer was found on the sample surface. Hence, the constant source solution had to be applied for the volume part of the profile,

$$
A=A_{0} \operatorname{erfc}\left(\frac{y}{\sqrt{4 D_{\mathrm{V}} t}}\right) \text {. }
$$

\subsection{Grain boundary diffusion}

The grain boundary diffusion contribution has to be evaluated depending on the specific kinetic regime as it was introduced by Harrison [44]. In the present study, the diffusion measurements were performed in the B-type kinetic regime and we used the exact solution of the Fisher model [45] for an instantaneous source, which was proposed by Suzuoka [46].

An analysis of the experimental diffusion profiles is exemplified in Fig. 2 where contributions of volume and grain boundary diffusion could directly be distinguished.

The careful analysis of the grain boundary diffusion contributions allowed reliably to obtain the volume diffusion coefficients which are of prime importance in the present paper. To this end, the penetration profiles were fitted accounting for both, volume [Eqs. (7) and (8)] and grain boundary [Suzuoka solution [46]] diffusion fluxes. The determined volume diffusion coefficients are given in Table 1.

\subsection{Temperature dependence}

The measured diffusion coefficients of all elements in $\mathrm{Co}_{10} \mathrm{Cr}_{10} \mathrm{Fe}_{10} \mathrm{Mn}_{10} \mathrm{Ni}_{60}$ and $\mathrm{Co}_{2} \mathrm{Cr}_{2} \mathrm{Fe}_{2} \mathrm{Mn}_{2} \mathrm{Ni}_{92}$ are plotted against the inverse homologous temperature $T_{m} / T$ where $T$ is the diffusion temperature and $T_{m}$ is the melting temperature. in Fig. 3. The melting temperatures of $\mathrm{Co}_{10} \mathrm{Cr}_{10} \mathrm{Fe}_{10} \mathrm{Mn}_{1}$ is $1659 \mathrm{~K}$ and $1743 \mathrm{~K}$ for $\mathrm{Co}_{2} \mathrm{Cr}_{2} \mathrm{Fe}_{2} \mathrm{Mn}_{2} \mathrm{Ni}_{92}$ [29]. Typically, the change of the tracer diffusion coefficients over a specific temperature range can be described by an Arrhenius dependence [47],

$$
D^{*}=D_{0}^{*} \exp \left(-\frac{Q}{R T}\right)
$$


Table 1: Temperatures $T$ and times $t$ of the diffusion experiments and the determined diffusion coefficients, $D^{*}$, for each material and isotope. A typical uncertainty of the determined diffusion coefficients does not exceed $\pm 20 \%$.

\begin{tabular}{c|c|c|c|c|c|c|c}
\hline \multirow{2}{*}{ material } & \multirow{2}{*}{$T(\mathrm{~K})$} & \multirow{2}{*}{$t(\mathrm{~s})$} & \multicolumn{5}{|c}{$D^{*}\left(10^{-17} \mathrm{~m}^{2} \mathrm{~s}^{-1}\right)$} \\
\cline { 4 - 7 } & & & ${ }^{51} \mathrm{Cr}$ & ${ }^{54} \mathrm{Mn}$ & ${ }^{57} \mathrm{Co}$ & ${ }^{59} \mathrm{Fe}$ & ${ }^{63} \mathrm{Ni}$ \\
\hline \multirow{3}{*}{$\mathrm{Co}_{10} \mathrm{Cr}_{10} \mathrm{Fe}_{10} \mathrm{Mn}_{10} \mathrm{Ni}_{60}$} & 1123 & 1036800 & 1.1 & 2.4 & 1.2 & 1.5 & 0.24 \\
& 1223 & 633120 & 5.0 & 8.1 & 3.7 & 6.2 & 2.6 \\
& 1273 & 501120 & 19.0 & 65.2 & 24.1 & 38.0 & 10.9 \\
\hline \multirow{3}{*}{$\mathrm{Co}_{2} \mathrm{Cr}_{2} \mathrm{Fe}_{2} \mathrm{Mn}_{2} \mathrm{Ni}_{92}$} & 1123 & 1036800 & 1.6 & 3.5 & 1.1 & 2.0 & 1.0 \\
& 1173 & 933120 & 6.6 & 6.9 & 4.8 & 10.9 & 5.0 \\
& 1223 & 604200 & 10.6 & 25.7 & & 10.7 & \\
& & 57600 & & & 9.9 & & 10.5 \\
& 1273 & 501120 & 30.9 & 33.3 & 20.0 & 67.1 & 49.8 \\
\hline
\end{tabular}

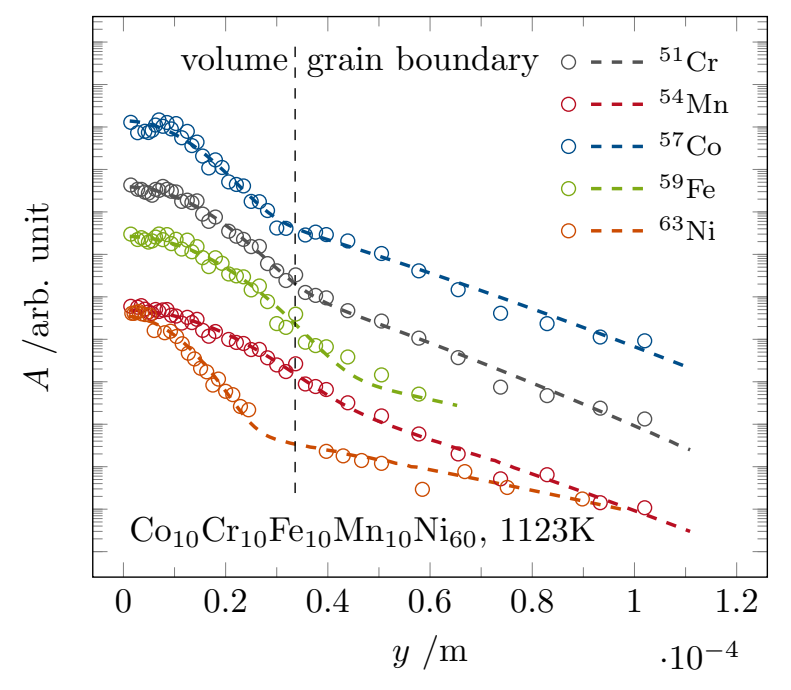

Figure 2: Measured tracer penetration profiles of ${ }^{51} \mathrm{Cr}$ (black), ${ }^{54} \mathrm{Mn}$ (red), ${ }^{57} \mathrm{Co}$ (blue), ${ }^{59} \mathrm{Fe}$ (olive) and ${ }^{63} \mathrm{Ni}$ (orange) in ${ }^{345}$ $\mathrm{Co}_{10} \mathrm{Cr}_{10} \mathrm{Fe}_{10} \mathrm{Mn}_{10} \mathrm{Ni}_{60}$ after a heat treatment at $1123 \mathrm{~K}$ for 10.6 days. Each circle symbolizes one data point at a specific depth $y$. The dashed lines correspond to the Suzuoka solutions [46] of the grain boundary diffusion problem accounting for both, volume and short-circuit diffusion. The profiles are shifted along the ordinate axis for a better visualization.

with the pre-exponential factor $D_{0}^{*}$ and the activation enthalpy $Q$. The determined activation enthalpies for bulk diffusion of all constituting elements in the alloys under consideration are summarized in Table 2.

As one can see, $\mathrm{Mn}$ is found to be the fastest element ${ }^{355}$ which features the lowest activation enthalpy for bulk diffusion in these alloys. The Ni atoms have shown the highest activation enthalpy, being larger than the activation enthalpy for Mn bulk diffusion by a factor of 1.5. Further, our experiments indicate that diffusion of $\mathrm{Fe}$ and $\mathrm{Cr}$ can be treated fairly similarly.

In Fig. 3, the presently measured tracer diffusion coefficients are compared to those in pure nickel and in the Cantor alloy $\left(\mathrm{Co}_{20} \mathrm{Cr}_{20} \mathrm{Fe}_{20} \mathrm{Mn}_{20} \mathrm{Ni}_{20}\right)$. Note that $\mathrm{Mn}$ diffusion in pure $\mathrm{Ni}$ was measured in the present investigation, too. The experiments reveal that the diffusion rates in the investigated alloys can be ordered as follows:

$\mathrm{Co}_{2} \mathrm{Cr}_{2} \mathrm{Fe}_{2} \mathrm{Mn}_{2} \mathrm{Ni}_{92}>\mathrm{Ni}>\mathrm{Co}_{10} \mathrm{Cr}_{10} \mathrm{Fe}_{10} \mathrm{Mn}_{10} \mathrm{Ni}_{60}>$ $\mathrm{Co}_{20} \mathrm{Cr}_{20} \mathrm{Fe}_{20} \mathrm{Mn}_{20} \mathrm{Ni}_{20}$.

Figure 3 suggests that, if analysed at a given homologous temperature, alloying of pure $\mathrm{Ni}$ by $8 \%$ of an equiatomic mixture of CoCrFeMn, i.e. by $2 \%$ of each element, enhances the diffusion rates of all elements, excluding Mn. The Mn diffusion rates are almost unaffected by this alloying, though a minor tendency towards retardation at lower $T / T_{m}$ values $\left(T / T_{m}<0.7\right)$ and an acceleration at higher temperatures, $T / T_{m}>0.7$, might be indicated.

Alloying by $40 \%$ of an equiatomic mixture of $\mathrm{CoCr}-$ FeMn decreases the diffusion coefficients to the level typical for element diffusion in pure Ni. Finally, somewhat sluggish diffusion in CoCrFeMnNi HEA might be stated, especially for Fe. Again, $\mathrm{Mn}$ is an exception from this 'rule'. When extrapolated to the melting point, $T / T_{m} \approx 1$, the diffusion coefficient of $\mathrm{Mn}$ in CoCrFeMnNi HEA becomes even higher than that in pure $\mathrm{Ni}$ or at least very similar values are observed.

\subsection{Atomic migration energy barriers}

The vacancy migration energy barriers, $\Delta E_{\mathrm{Mig}}$, in a HEA are expected to strongly depend on the chemical environment of the vacancy. All neighboring atoms can jump into the vacant site and given the chemical complexity of the alloy the activation energy for all theses jumps will be 
a)
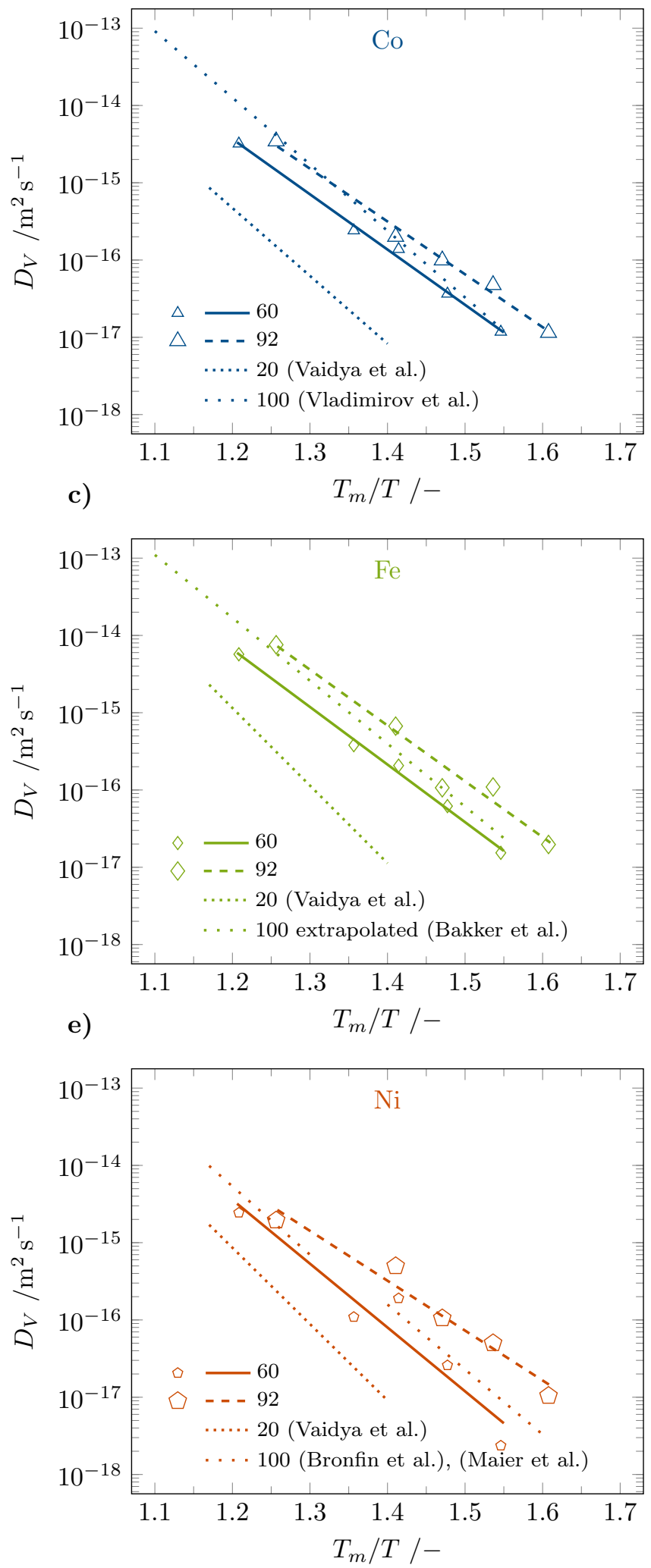

b)
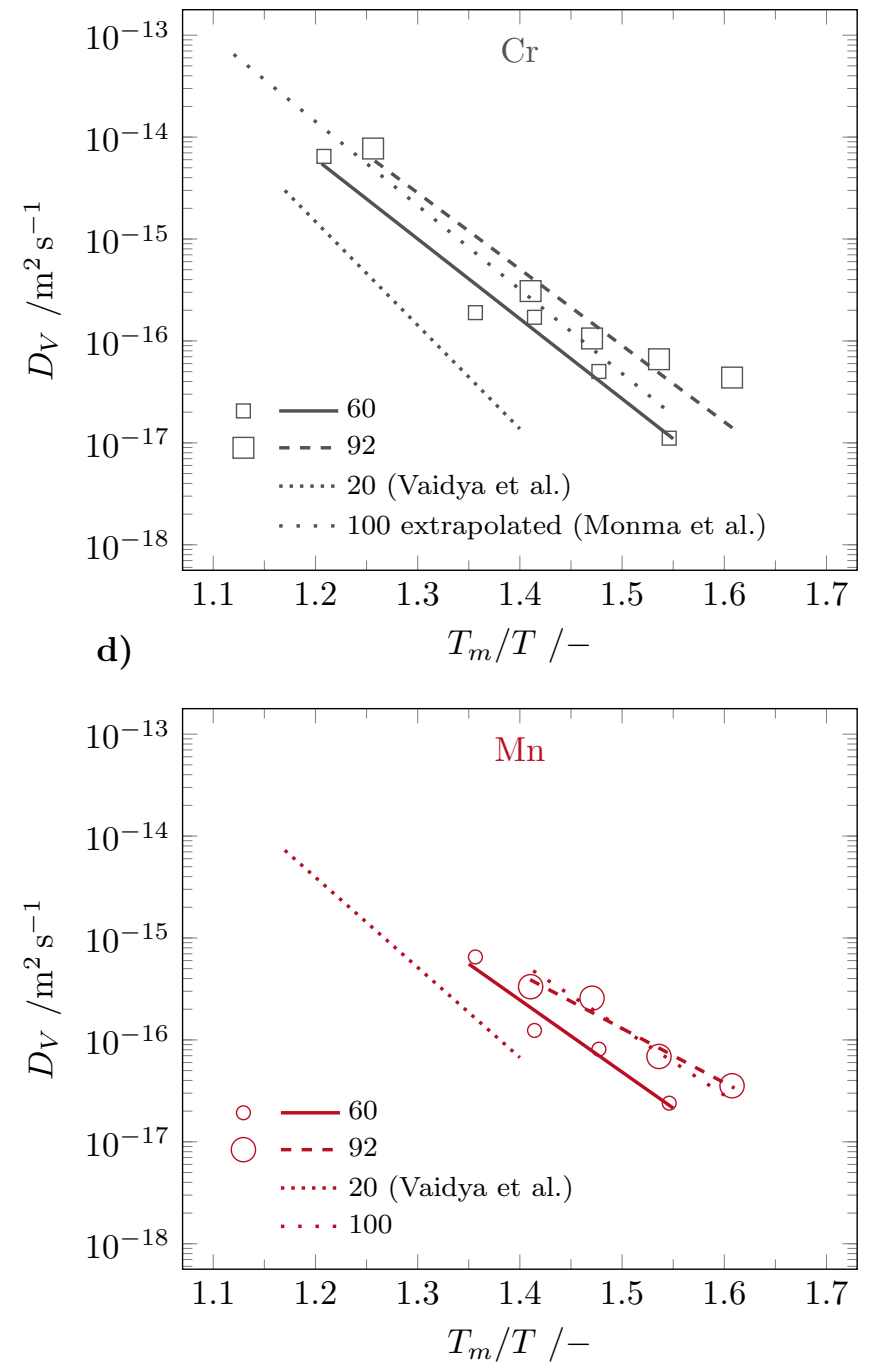

Figure 3: The measured volume diffusion coefficients against the inverse homologous temperature, $T_{m} / T$, where $T$ is the diffusion temperature

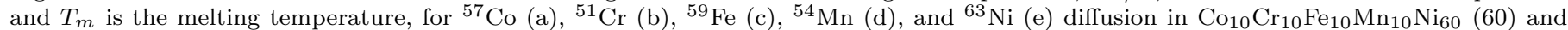
$\mathrm{Co}_{2} \mathrm{Cr}_{2} \mathrm{Fe}_{2} \mathrm{Mn}_{2} \mathrm{Ni} 92$ (92) alloys in comparison to pure $\mathrm{Ni}(100)$ [48, 49, 50, 51, 52] and the $\mathrm{Co}_{20} \mathrm{Cr}_{20} \mathrm{Fe}_{20} \mathrm{Mn} 20 \mathrm{Ni}_{20} \mathrm{HEA}(20)$ [9, 13]. $\mathrm{Note}$ that the diffusion coefficients at $1373 \mathrm{~K}$ were measured in our previous work [29] and Mn diffusion in pure Ni was measured in the present work, too. The diffusion coefficients in the two alloys are distinguished by the symbol size. 
Table 2: The vacancy migration energies, $E_{\mathrm{vac}_{m}}$, determined by atomistic simulations and the measured diffusion activation enthalpies, $Q$, for $\mathrm{Co}_{10} \mathrm{Cr}_{10} \mathrm{Fe}_{10} \mathrm{Mn}_{10} \mathrm{Ni}_{60}$ and $\mathrm{Co}_{2} \mathrm{Cr}_{2} \mathrm{Fe}_{2} \mathrm{Mn}_{2} \mathrm{Ni}_{92}$. All data is given in $\mathrm{kJ}$ mol-1. For comparison, the data for pure $\mathrm{Ni}$ and the CoCrFeMnNi HEA are presented, too. Note that Mn diffusion in pure Ni was measured in the present work.

\begin{tabular}{l|c|c|c|c|c|c|c|c}
\hline \multirow{2}{*}{ Tracer } & \multicolumn{2}{|c|}{$\mathrm{Co}_{20} \mathrm{Cr}_{20} \mathrm{Fe}_{20} \mathrm{Mn}_{20} \mathrm{Ni}_{20}$} & \multicolumn{2}{|c|}{$\mathrm{Co}_{10} \mathrm{Cr}_{10} \mathrm{Fe}_{10} \mathrm{Mn}_{10} \mathrm{Ni}_{60}$} & $\mathrm{Co}_{2} \mathrm{Cr}_{2} \mathrm{Fe}_{2} \mathrm{Mn}_{2} \mathrm{Ni}_{92}$ & \multicolumn{2}{c}{$\mathrm{Ni}$} \\
\cline { 2 - 8 } & $E_{\mathrm{vac}_{m}}$ & $Q$ & $E_{\mathrm{vac}_{m}}$ & $Q$ & $E_{\mathrm{vac}_{m}}$ & $Q$ & $E_{\mathrm{vac}_{m}}$ & $Q$ \\
\hline${ }^{51} \mathrm{Cr}$ & 54.3 & $313 \pm 13[13]$ & 89.5 & $249 \pm 24$ & 114.7 & $247 \pm 19$ & 158.8 & $272.6[49]$ \\
${ }^{54} \mathrm{Mn}$ & 53.4 & $272 \pm 13[13]$ & 89.7 & $224 \pm 38$ & 116.0 & $175 \pm 28$ & 140.1 & $219 \pm 8$ \\
${ }^{57} \mathrm{Co}$ & 62.9 & $270 \pm 22[13]$ & 101.0 & $227 \pm 9$ & 124.6 & $226 \pm 13$ & 160.3 & $285.1[48]$ \\
${ }^{59} \mathrm{Fe}$ & 56.1 & $309 \pm 11[13]$ & 89.1 & $237 \pm 10$ & 113.1 & $238 \pm 25$ & 138.1 & $269.4[50]$ \\
${ }^{63} \mathrm{Ni}$ & 62.2 & $304 \pm 9[9]$ & 96.7 & $262 \pm 47$ & 118.4 & $213 \pm 24$ & 142.7 & $292.6[51]$ \\
& & & & & & & & \\
\hline
\end{tabular}

different. The determination of the migration energy dis-405 tribution requires sampling of a great number of chemical environments.

Using the interatomic potentials of Choi et al. [19], we use the nudged-elastic band method to determine the vacancy migration barrier for different atoms exchanging ${ }_{410}$ position with the vacancy. By randomly sampling different chemical environments we obtain the distributions of $\Delta E_{\mathrm{Mig}}$ shown in Fig. 4. Each plot shows the distribution (number fraction) of the concentration-dependent migration barriers for one migrating species. It can be seen that $\mathrm{Mn}$ has the lowest mean migration energy barrier combined with a rather narrow energy distribution. Cr has a slightly higher mean migration barrier but shows a significantly broader distribution. Co and $\mathrm{Ni}$ both are predicted to have the highest vacancy migration energies. Moreover, as the $\mathrm{Ni}$ concentration increases, i.e. with a transition $\mathrm{to}_{420}$ more dilute Ni-based alloys, the means of all distributions shift to higher energies. Tab. 3 summarizes the mean of the peak positions and their width, where $\mu$ denotes the mean of the fitted Gaussian and $\sigma$ its standard deviation.

It can also be seen that as the $\mathrm{Ni}$ concentration in- ${ }_{425}$ creases, the probability of having a Ni-rich environment around a vacancy also increases leading to a reduction in peak width for all samples. This is also accompanied by a splitting of this major peak. This corresponds to binning of the Ni-rich environments and all other environments ${ }_{430}$ around the vacancy. The dilute-limit migration energy barrier, which corresponds to a single solute atom in a pure Ni matrix, is highlighted by a $\times$ symbol. It can be seen that this energy corresponds to the main peak in the $x=92$ sample indicating a high probability for a pure $\mathrm{Ni}_{435}$ neighborhood.

Comparing our findings with the vacancy migration barriers reported by Choi et al. [19] we find the same migration energy distribution if we superimpose the different elemental histograms given in Fig 4 . This results is ex- $^{-}$ pected given that both results are based on the same interatomic potential. Nevertheless, the significantly larger number of migration barriers sampled for this study (5604

400 in the present study against the 390 of Choi et al. [19] for the equimolar Cantor alloy) allows for a species resolved ${ }_{445}$ migration barrier distribution instead of one global migration energy distribution.

Mizuno et al. [20] studied the migration barrier using small special quasi-random structures (SQS) using DFT. These SQS are equimolar and designed to mimic a random chemical environment on a small scale. We find that many local chemical environments are not perfectly equimolar or perfectly random given the large number of combinatoric degrees of freedom on the lattice. These fluctuations cannot be captured using small SQS.

\subsection{Tracer correlation factors from KMC simulations}

The solid lines in Fig 5 show the tracer correlation factor $f$ calculated from the vacancy migration energy barrier distributions given in Fig. 4. The data shows that the correlation factor for the faster diffusing elements ( $\mathrm{Mn}$ and $\mathrm{Fe}$ ) with the lower migration energy barrier is reduced compared to the other elements in the alloy. Moreover, the concentration dependence of $f$ shows that $f$ decreases further as the $\mathrm{Ni}$ concentration increases. As the $\mathrm{Ni}$ concentration approaches 1 , the $\mathrm{Ni}$ correlation factor tends towards the theoretical $f$ value for low defect concentrations of 0.78146 [53].

Both observations can be explained by looking at the energy landscape around the vacancy. Three different cases are shown schematically in Fig. 5 (a-c). Here green bonds correspond to low migration energy jumps, while red bonds indicate high energy jumps (migration energies are schematically shown in $(d)$ ). The initial vacancy position is marked by a ' $\mathrm{V}$ '. The first jump is always 'A' and ' $\mathrm{V}$ ' exchanging sites (solid arrow). In (a) and (c) this would be a low energy barrier jump, while in (b) this requires crossing a high energy barrier. Successive jumps with a low energy barrier and therefore a high probability are indicated by dashed arrows. > From this simplified picture we can now learn that in (a) an atom with a low migration barrier has a high probability of jumping forwards and backwards leading to two diffusive jumps without net mass transport therefore leading to a more correlated tracer diffusivity. From (b) we can see that this successive forwards-backwards jump is less likely for atoms having a high migration energy barrier. These atoms are more likely to jump once and have the vacancy progress further in the crystal instead of jumping backwards leading to a correlation factor closer to one. (c) shows a similar situation in a system where the high migration barrier atoms make up a larger fraction (similar to the $x_{\mathrm{Ni}}=92$ sample). Once an atom with a low 
Table 3: Mean, $\mu$, and standard deviation, $\sigma$, of the distribution of the activation energies obtained from the NEB calculations shown in Fig. 4. $x_{\mathrm{Ni}}$ is given in at. $\%, \mu$ and $\sigma$ are given in $\mathrm{eV} /$ at. $x_{\mathrm{Ni}}=100$ at. $\%$ corresponds to the case where a single solute is added to the sample. This data is used as input for the KMC simulations.

\begin{tabular}{l|rr|rr|rr|rr|rr}
\hline$x_{\mathrm{Ni}}$ & \multicolumn{2}{|c|}{ Co } & \multicolumn{2}{c|}{$\mathrm{Cr}$} & \multicolumn{2}{c|}{$\mathrm{Fe}$} & \multicolumn{2}{|c}{$\mathrm{Mn}$} & \multicolumn{2}{c}{$\mathrm{Ni}$} \\
& $\mu$ & $\sigma$ & $\mu$ & $\sigma$ & $\mu$ & $\sigma$ & $\mu$ & $\sigma$ & $\mu$ & $\sigma$ \\
\hline 20 & 1.045 & 0.224 & 0.869 & 0.295 & 0.690 & 0.164 & 0.493 & 0.168 & 0.985 & 0.208 \\
60 & 1.310 & 0.172 & 1.261 & 0.267 & 0.862 & 0.163 & 0.707 & 0.135 & 1.216 & 0.166 \\
80 & 1.445 & 0.122 & 1.465 & 0.192 & 0.975 & 0.140 & 0.775 & 0.111 & 1.339 & 0.115 \\
92 & 1.570 & 0.079 & 1.563 & 0.1444 & 1.048 & 0.083 & 0.820 & 0.086 & 1.421 & 0.085 \\
100 & 1.651 & & 1.625 & & 1.073 & & 0.850 & & 1.471 & \\
\hline
\end{tabular}

activation barrier is found by the vacancy the probability of it jumping back and forth around the same position ${ }_{485}$ 450 becomes highly probable leading to a highly correlated diffusion trajectory for the low migration barrier species.

\subsection{Diffusion constants from KMC simulations}

The KMC simulations give us the diffusion trajectories ${ }_{490}$ of all atoms and the vacancy contained in the sample. Using this data the diffusion coefficient $D_{i}$ can be calculated from the mean squared displacement $R_{i}$ for each species $i$ given the relation,

$$
\left\langle R_{i}^{2}\right\rangle=\frac{1}{6} D_{i} t
$$

where $t$ is the total time. In practice $D_{i}$ is obtained from a linear fit of $\left\langle R_{i}^{2}\right\rangle$ over $t$ [54].

Fig. 6 shows $D_{i}$ on an Arrhenius scale for the different elements and $\mathrm{Ni}$ concentrations in the sample. We $\operatorname{can}^{500}$ see that for all samples and all elements $D_{i}$ decreases as the $\mathrm{Ni}$ concentration in the sample increases. Moreover, the diffusion is always higher in the alloy compared to the dilute limit of a single solute in a pure $\mathrm{Ni}$ matrix $\left(x_{\mathrm{Ni}}=\right.$ 100).

Further examination of $D_{i}$ reveals that it follows the trend one would expect from the activation energy barriers presented in Table 3 and transition state theory. A high migration energy corresponds to a lower diffusivity while a lower barrier leads to a higher $D_{i}$. There are two main fac- ${ }^{510}$ tors explaining this relationship. First, as shown in Fig. 5, while there is a contribution of the correlation factor $f$ to the diffusivity in these alloys, it changes only by about one order of magnitude, which is not sufficient to overcome the differences in $D_{i}$ stemming from the significant difference ${ }^{515}$ in $\Delta E_{i}$ between elements and concentrations. Second, the data shown in Fig. 6 does not account for concentration or temperature dependent differences in the vacancy concentration which would act as a scaling factor on the individual $D$ values (Eq. 5 ). The vacancy formation energies ${ }^{520}$ cannot be accounted for as there is no applicable theory on how to average the vacancy formation energies for each species and how to include the concentration dependant both been defined as the given constants for the KMC simulations, we normalized the element-specific diffusion coefficients, $D_{i}$, by the diffusion coefficient of Fe, $D_{\mathrm{Fe}}$. From Eq. (4) and (5) it can be seen that $D_{i} / D_{\mathrm{Fe}}$ is obviously independent of $c_{\mathrm{Vac}}$ and $\nu_{0}$ as they are constant for one sample at a given temperature (neglecting simultaneously the variation of the element-specific migration entropies). The specific choice of Fe is somewhat arbitrary and it is motivated by a lowest scatter of the experimental points on the corresponding Arrhenius plots for all alloys under consideration. The comparison of experimental tracer diffusion coefficients with those obtained from the KMC simulations reveals a good qualitative agreement and the differences are caused probably by the interatomic potentials used in the present work.

Figure 7 a shows $D_{i} / D_{\mathrm{Fe}}$ as a function of the Ni concentration at a constant absolute temperature of $1123 \mathrm{~K}$. A general increasing trend of the normalized diffusion coefficients from pure Ni to the Cantor alloy which is observed for all solutes can be reproduced by our simulations, too. Qualitatively, the experimental and simulation data agree especially well for $\mathrm{Mn}$ and $\mathrm{Ni}$, while for $\mathrm{Cr}$ a significantly stronger increase of the normalized diffusion coefficient, $D_{\mathrm{Cr}} / D_{\mathrm{Fe}}$, is predicted, from less than 0.1 (pure $\mathrm{Ni}$ ) to about unity (HEA). Experimentally, these values are equal to almost 1 for all compositions. The normalized $\mathrm{Ni}$ diffusion coefficient, $D_{\mathrm{Ni}} / D_{\mathrm{Fe}}$, decreases first from about 0.7 (pure Ni) to 0.6 (the concentrated alloy) and than increases to about 0.8 (the Cantor alloy).

When analysed at a constant homologous temperature of $0.8 T_{m}$, Figure $7 \mathrm{~b}$, the normalized diffusion coefficients group within a relatively narrow interval $0.2<D_{i} / D_{\mathrm{Fe}}<$ 2 . The atomistic simulations reproduce well the concentration trends observed for the diffusion of $\mathrm{Ni}$ and $\mathrm{Co}$ atoms, even quantitatively and for other elements qualitatively correct tendencies are reproduced.

$\mathrm{Mn}$ is probably the most important exception. While atomistic calculations predict $D_{\mathrm{Mn}} / D_{\mathrm{Fe}} \geq 1$ for all compositions at $T=0.8 T_{m}$, a significant decrease of the normalized diffusion coefficient is seen in concentrated alloys that is reversed in CoCrFeMnNi HEA.

\subsection{Comparison between experiment and simulation}

To avoid the uncertainties related to the vacancy concentration and the attempt frequencies $\nu_{0}$, which have 


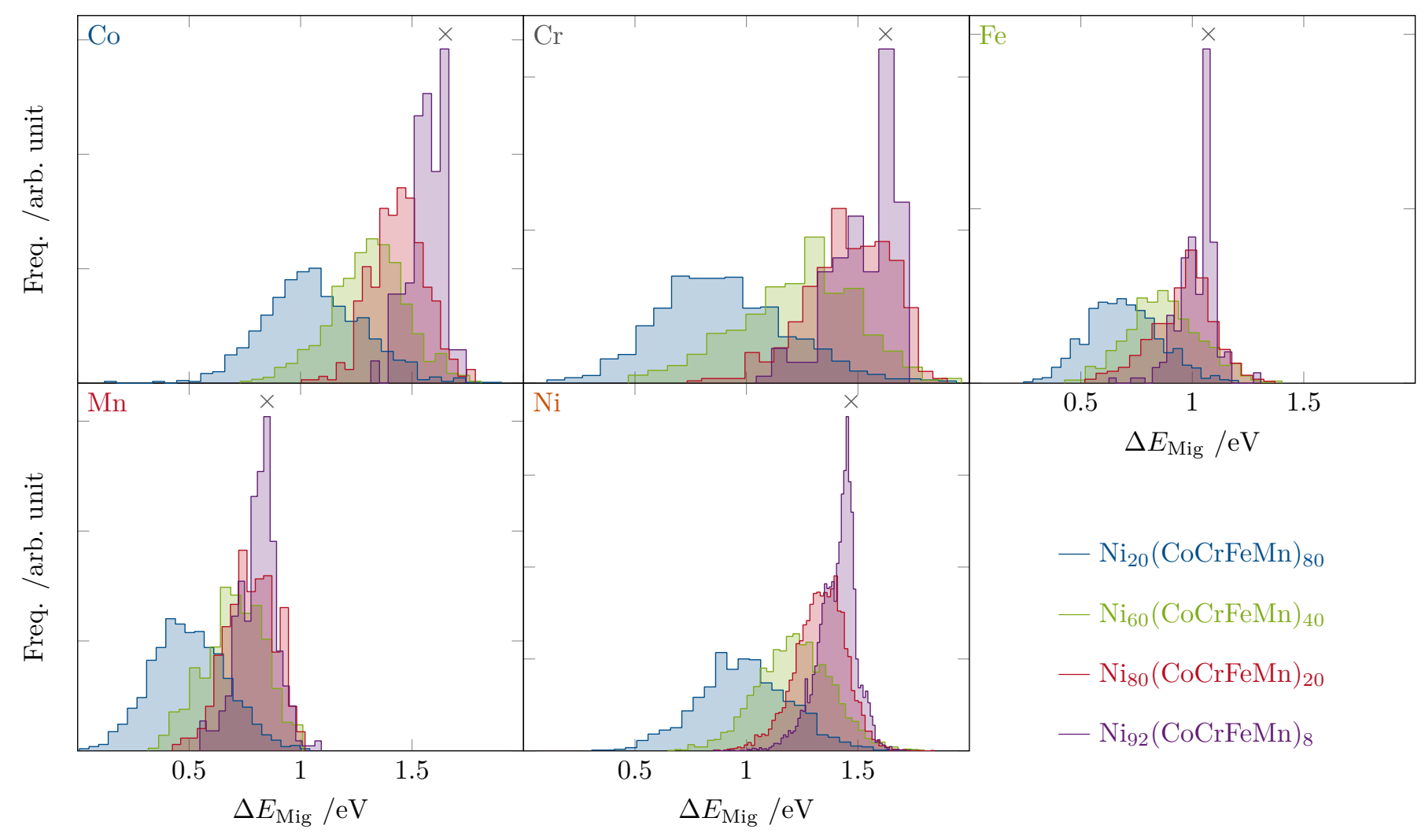

Figure 4: Distribution of the vacancy migration energy barriers $\Delta E_{\mathrm{Mig}}$ in different $\mathrm{Ni}_{x}(\mathrm{CoCrFeMn})_{100-x}$ alloys. Freq. is the frequency of the different $\Delta E_{\mathrm{Mig}}$. The label in the top right denotes the species of the migrating atom. The $\times$ denotes the diffusion activation energy for the migrating element in a pure FCC Ni matrix (corresponding to the dilute limit). The total data set includes about 29000 vacancy jumps.

\section{Conclusions}

In the present work, volume diffusion of all constituting elements is measured in $\mathrm{Co}_{10} \mathrm{Cr}_{10} \mathrm{Fe}_{10} \mathrm{Mn}_{10} \mathrm{Ni}_{60}$ and $\mathrm{Co}_{2} \mathrm{Cr}_{2} \mathrm{Fe}_{2} \mathrm{Mn}_{2} \mathrm{Ni}_{92}$ at temperatures from $1123 \mathrm{~K}$ to $1373 \mathrm{~K}$. The two alloys were shown to form a single-phase FCC solid solution at all measured temperatures. For complete-555 ness, $\mathrm{Mn}$ diffusion in pure $\mathrm{Ni}$ is measured, too, to provide a whole data set for reliable evaluation of the elementspecific diffusion coefficients along the $\mathrm{Ni}-\mathrm{CoCrFeMnNi}$ cut of the multi-component phase diagram. Simultaneously, the vacancy formation and migration enthalpies in 560 these alloys are examined using atomistic simulations with empirical interatomic potentials.

Reconsidering the measurements and the simulations, the following conclusions are reached:

- The measured activation enthalpies are varying be-565 tween $175 \mathrm{~kJ} \mathrm{~mol}^{-1}$ and $247 \mathrm{~kJ} \mathrm{~mol}^{-1}$ for $\mathrm{Co}_{2} \mathrm{Cr}_{2} \mathrm{Fe}_{2} \mathrm{Mn}_{2} \mathrm{Ni}_{92}$ and from $224 \mathrm{~kJ} \mathrm{~mol}^{-1}$ to $262 \mathrm{~kJ} \mathrm{~mol}^{-1}$ for $\mathrm{Co}_{10} \mathrm{Cr}_{10} \mathrm{Fe}_{10} \mathrm{Mn}_{10} \mathrm{Ni}_{60}$.

- On the inverse homologous temperature scale, the data suggest that bulk diffusion is enhanced by small s70 $_{50}$ additions of a solute mixture due to a higher vacancy concentration. Further addition of the equiatomic $\mathrm{CoCrFeMn} \mathrm{mixture} \mathrm{(10} \mathrm{at. \%} \mathrm{each)} \mathrm{leads} \mathrm{to} \mathrm{a} \mathrm{retar-}$ dation of the diffusion rates in comparison to solute diffusion in pure Ni. In general, this cannot be taken as a clear evidence for 'sluggish' diffusion, since the effect depends strongly on the temperature and especially on the solute.

- We employed high-throughput sampling of more than 29000 vacancy migration barriers to determine the species and concentration dependent migration barrier distributions. Here, we find that $\mathrm{Mn}$ has the lowest energy barrier, followed by $\mathrm{Cr}$ or $\mathrm{Fe}$, depending on the sample composition. Co and Ni show the highest barriers.

- We find that the mean of the energy barrier distributions is most strongly affected by the species of the diffusing atom, while the width correlates with the sample composition and decreases as the sample shifts from HEA to dilute solid solution.

- The tracer correlation factors for each element in the HEA obtained from our KMC simulations correlate with the respective mean of the migration barrier distribution. Fast diffusing elements with low barriers show highly correlated jumps, especially as the concentration of high vacancy migration barrier elements in the alloy increases.

- The finite width of the vacancy migration barrier 

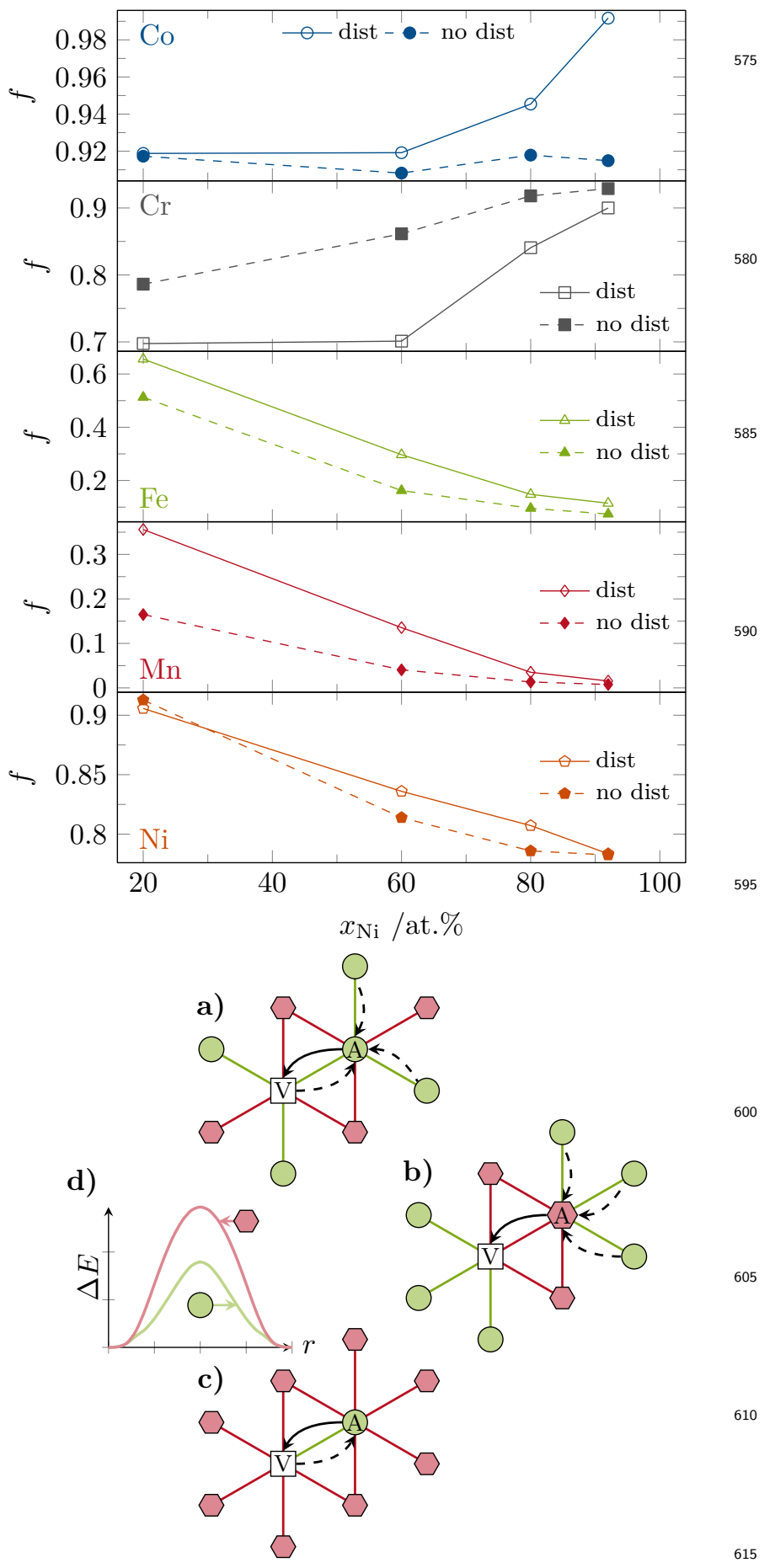

Figure 5: Correlation factors obtained from the KMC simulation after $10^{8}$ steps. Solid lines represent KMC results where the migration energy barriers are taken with a finite width (Tab. 3). Dashed lines show $f$ with a constant, unimodal activation barrier activation620 barrier, which corresponds to the conventional random alloy model. This data corresponds to the random alloy model. In all cases $f$ was sampled at $1123 \mathrm{~K}$. (a-c) show examples of different chemical environments around the vacancy. Red bonds correspond to a high migration barrier jump, while green bonds represent low migration625 barrier jumps. The first jump is indicated by a solid arrow, while most probable successive jumps are indicated by dashed lines. (d) schematically shows the low and high migration energy $\Delta E$ over the reaction coordinate $r$. Fig. A.10 shows the same $f$ data in a singular plot for easier comparison of the different samples. modifies the tracer correlation factors compared to the conventional random alloy model. Species with low migration barriers of broad migration barrier distributions are impacted most strongly.

- The comparison between measurements and simulation indicates that our model provides a reasonable description. The absolute diffusion coefficients can not be reproduced so far, since there is no no applicable theory on how to average the vacancy formation energies for each species and how to further include the concentration dependant configurational entropy of the vacancy. Neglecting the vacancy concentration by normalizing the diffusion coefficients on one diffusor $(\mathrm{Fe})$, all observable trends of the measurements could be replicated.

- The element-specific correlation factors are strongly affected by the heterogeneities of local chemical environments of a diffusing vacancy causing strong deviations from predictions of a mean-field random alloy model.

\section{Acknowledgments}

Funding by Deutsche Forschungsgemeinschaft (DFG) via SPP2006, projects WI 1899/32-1 and STU 611/2-1, is gratefully acknowledged. Calculations for this research were conducted on the Lichtenberg high performance computer of the TU Darmstadt.

\section{References}

[1] R. E. Hummel, Understanding Materials Science, Springer, 2004. doi:10.1007/b137957.

URL http://www.ebook.de/de/product/3014120/rolf_e_ hummel_understanding_materials_science.html

[2] J.-W. Yeh, S.-K. Chen, S.-J. Lin, J.-Y. Gan, T.-S. Chin, T.-T. Shun, C.-H. Tsau, S.-Y. Chang, Nanostructured high-entropy alloys with multiple principal elements: Novel alloy design concepts and outcomes, Advanced Engineering Materials 6 (5) (2004) 299-303. doi:10.1002/adem.200300567.

URL http://dx.doi.org/10.1002/adem.200300567

[3] B. Cantor, I. Chang, P. Knight, A. Vincent, Microstructural development in equiatomic multicomponent alloys, Materials science and engineering a-Structural materials properties microstructure and processing 375-377 (2004) 213-218. doi: 10.1016/j.msea.2003.10.257.

[4] D. Miracle, O. Senkov, A critical review of high entropy alloys and related concepts, Acta Materialia 122 (2017) 448 - 511. doi:http://dx.doi.org/10.1016/j.actamat.2016.08.081.

URL http://www.sciencedirect.com/science/article/pii/ S1359645416306759

[5] L. Lilensten, J.-P. Couzinié, L. Perrière, A. Hocini, C. Keller, G. Dirras, I. Guillot, Study of a bcc multi-principal element alloy: Tensile and simple shear properties and underlying deformation mechanisms, Acta Materialia 142 (2018) 131 - 141. doi:https://doi.org/10.1016/j.actamat.2017.09.062.

URL http://www.sciencedirect.com/science/article/pii/ S1359645417308327

[6] B. Gludovatz, A. Hohenwarter, D. Catoor, E. H. Chang, E. P. George, R. O. Ritchie, A fracture-resistant high-entropy alloy for cryogenic applications, Science 345 (6201) (2014) 
a)
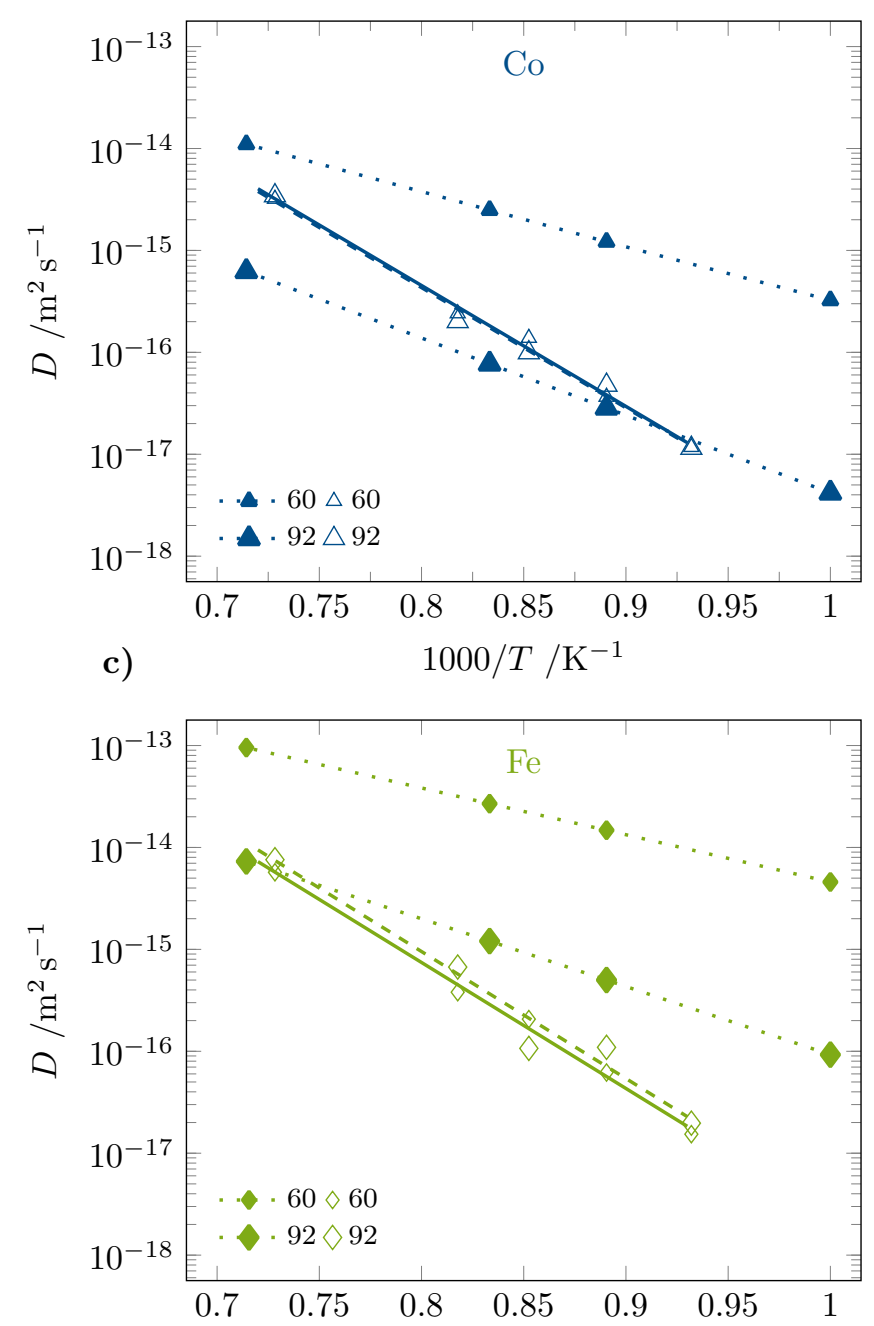

e)

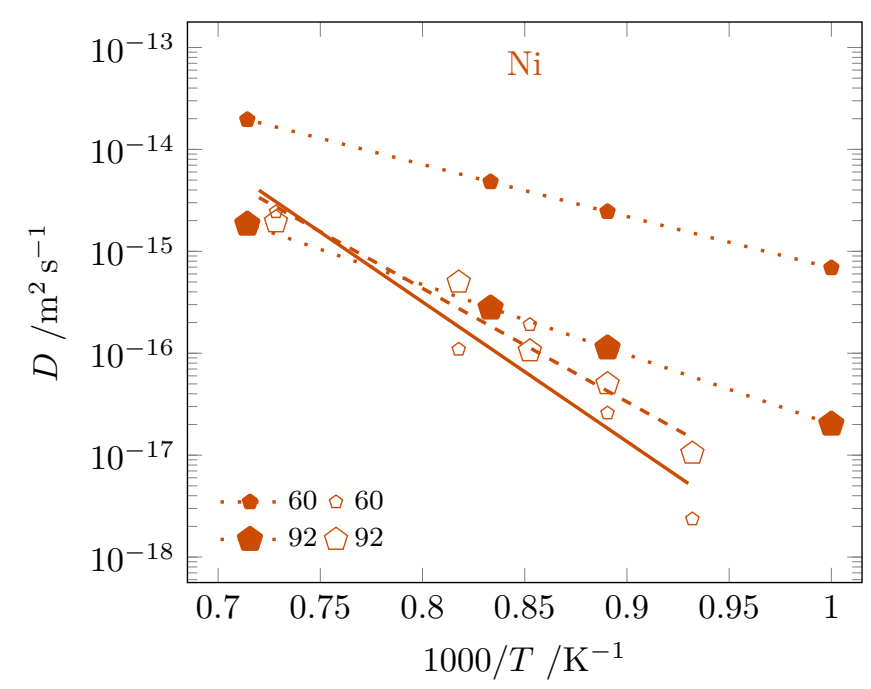

b)
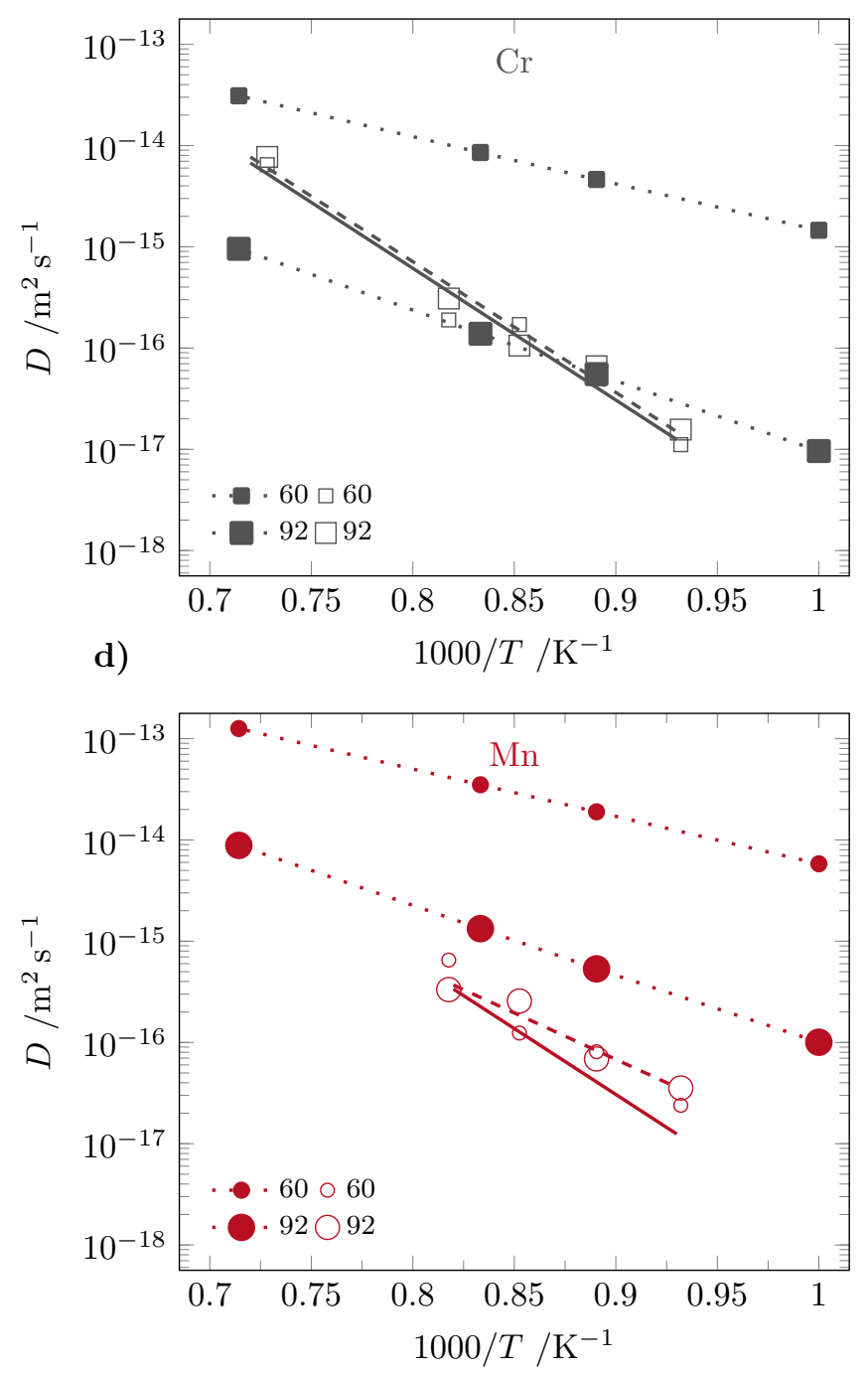

Figure 6: Arrhenius plots for element-dependent diffusion coefficients (a) - (e) in $\mathrm{Co}_{10} \mathrm{Cr}_{10} \mathrm{Fe}_{10} \mathrm{Mn}_{10} \mathrm{Ni}_{60}$ ( $\left.\mathrm{small} \mathrm{symbols}\right)$ and $\mathrm{Co}_{2} \mathrm{Cr}_{2} \mathrm{Fe}_{2} \mathrm{Mn}_{2} \mathrm{Ni}_{92}$ (large symbols). The simulation data (filled symbols and dotted lines) are presented for a constant vacancy concentration of $3.125 \times 10^{-5}$. The experimentally measured diffusion coefficients are given by open symbols. The solid and dashed lines represent the corresponding Arrhenius fits. 


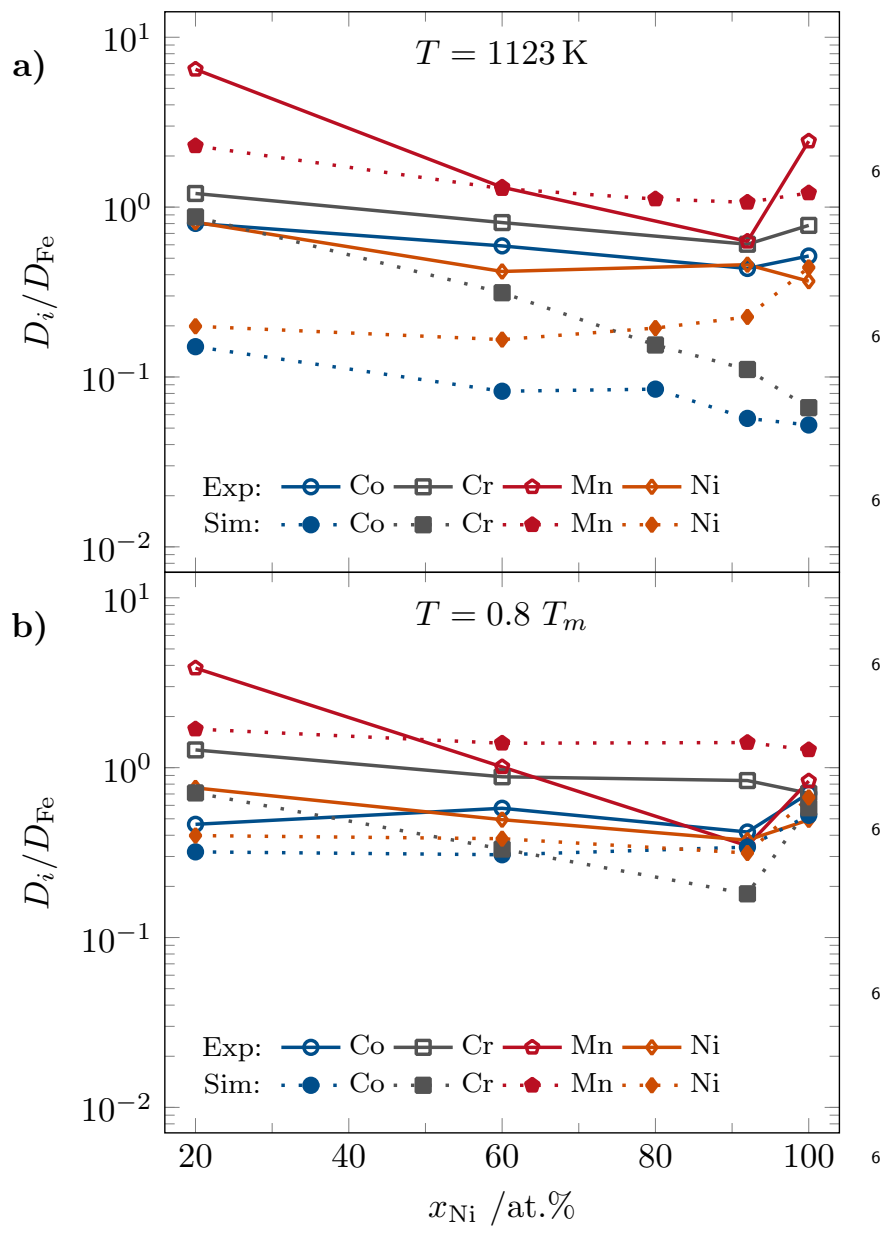

Figure 7: Comparison of element-specific diffusion coefficients normalized by the corresponding diffusion coefficients of Fe, $D_{i} / D_{\mathrm{Fe}}{ }^{695}$ as predicted by simulation (filled symbols and dashed lines) and determined experimentally (open symbols and solid lines). In a), the measured and calculated data are compared at $1123 \mathrm{~K}$, whereas in b), the comparison is done at $T=0.8 T_{m}$.

1153-1158. arXiv:http://science.sciencemag.org/content/ 345/6201/1153.full.pdf, doi:10.1126/science.1254581.

URL http://science.sciencemag.org/content/345/6201/705 1153

[7] J.-W. Yeh, Recent progress in high-entropy alloys, Annales de chimie 31 (6) (2006) 633-648. doi:10.3166/acsm.31.633-648.

[8] K.-Y. Tsai, M.-H. Tsai, J.-W. Yeh, Sluggish diffusion in cocrfemnni high-entropy alloys, Acta Materialia 61 (13) (2013) 4887 - 4897. doi:http://doi.org/10.1016/j.actamat. 2013. 04.058.

URL http://www.sciencedirect.com/science/article/pii/ S1359645413003431

[9] M. Vaidya, S. Trubel, B. Murty, G. Wilde, S. Divinski, Ni tracer diffusion in cocrfeni and cocrfemnni high entropy alloys, Journal of Alloys and Compounds 688, Part B (2016) $994-1001$. doi:http://doi.org/10.1016/j.jallcom.2016.07.239.

URL http://www.sciencedirect.com/science/article/pii/ S0925838816322745

[10] E. Pickering, N. Jones, High-entropy alloys: a critical assess- ${ }^{720}$ ment of their founding principles and future prospects, International Materials Reviews 61 (3) (2016) 183-202.

[11] M. Vaidya, K. Pradeep, B. Murty, G. Wilde, S. Divinski, Radioactive isotopes reveal a non sluggish kinetics of grain boundary diffusion in high entropy alloys, Scientific reports 7 (1)
[12] S. V. Divinski, A. V. Pokoev, N. Esakkiraja, A. Paul, A mystery of" sluggish diffusion" in high-entropy alloys: the truth or a myth?, in: Diffusion Foundations, Vol. 17, Trans Tech Publ, 2018, pp. 69-104.

[13] M. Vaidya, K. Pradeep, B. Murty, G. Wilde, S. Divinski, Bulk tracer diffusion in cocrfeni and cocrfemnni high entropy alloys, Acta Materialia 146 (2018) 211-224.

[14] A. Paul, Comments on "sluggish diffusion in $\mathrm{co}-\mathrm{cr}-\mathrm{fe}-\mathrm{mn}-\mathrm{ni}$ high-entropy alloys" by ky tsai, mh tsai and jw yeh, acta materialia 61 (2013) 4887-4897, Scripta Materialia 135 (2017) $153-157$

[15] I. V. Belova, G. E. Murch, Comments on "experimental assessment of the thermodynamic factor for diffusion in cocrfeni and cocrfemnni high entropy alloys", Scripta Materialia 172 (2019) $110-112$.

[16] Y. N. Osetsky, L. K. Béland, A. V. Barashev, Y. Zhang, On the existence and origin of sluggish diffusion in chemically disordered concentrated alloys, Current Opinion in Solid State and Materials Science 22 (3) (2018) 65-74.

[17] S. Divinski, O. Lukianova, G. Wilde, A. Dash, N. Esakkiraja, A. Paul, High-entropy alloys: Diffusion, Encyclopedia of Materials: Science and Technology (2020).

[18] J. Dabrowa, M. Danielwski, State-of-the-art diffusion studies in the high entropy alloys, Metal 10 (2020) 347. doi:10.3390/ met10030347.

[19] W.-M. Choi, Y. H. Jo, S. S. Sohn, S. Lee, B.-J. Lee, Understanding the physical metallurgy of the CoCrFeMnNi high-entropy alloy: An atomistic simulation study, npj Comput Mater 4 (1) (2018) 1. doi:10.1038/s41524-017-0060-9.

5 [20] M. Mizuno, K. Sugita, H. Araki, Defect energetics for diffusion in $\mathrm{CrMnFeCoNi}$ high-entropy alloy from first-principles calculations, Computational Materials Science 170 (2019) 109163. doi:10.1016/j.commatsci.2019.109163.

[21] K. Sugita, N. Matsuoka, M. Mizuno, H. Araki, Vacancy formation enthalpy in CoCrFeMnNi high-entropy alloy, Scripta Materialia 176 (2020) 32-35. doi:10.1016/j.scriptamat.2019.09. 033.

[22] E.-W. Huang, H.-S. Chou, K. N. Tu, W.-S. Hung, T.-N. Lam, C.-W. Tsai, C.-Y. Chiang, B.-H. Lin, A.-C. Yeh, S.-H. Chang, Y.-J. Chang, J.-J. Yang, X.-Y. Li, C.-S. Ku, K. An, Y.W. Chang, Y.-L. Jao, Element Effects on High-Entropy Alloy Vacancy and Heterogeneous Lattice Distortion Subjected to Quasi-equilibrium Heating, Sci Rep 9 (1) (2019) 14788. doi: $10.1038 / s 41598-019-51297-4$.

[23] I. Belova, G. Murch, Tracer correlation factors in the random alloy, Philosophical Magazine A 80 (7) (2000) 1469-1479.

[24] I. Belova, G. Murch, Analysis of intrinsic diffusivities in multicomponent alloys, Philosophical magazine letters 81 (9) (2001) $661-666$.

[25] J. R. Manning, Correlation factors for diffusion in nondilute alloys, Physical Review B 4 (4) (1971) 1111.

[26] M. Laurent-Brocq, L. Perrière, R. Pirès, Y. Champion, From high entropy alloys to diluted multi-component alloys: Range of existence of a solid-solution, Materials \& Design 103 (2016) 84 - 89. doi:https://doi.org/10.1016/j.matdes.2016.04.046. URL http://www.sciencedirect.com/science/article/pii/ S0264127516305202

[27] M. Laurent-Brocq, L. Perrière, R. Pirès, F. Prima, P. Vermaut, Y. Champion, From diluted solid solutions to high entropy alloys: On the evolution of properties with composition of multicomponents alloys, Materials Science and Engineering: A 696 (2017) 228 - 235. doi :https ://doi.org/10.1016/j.msea. 2017. 04.079 .

URL http://www.sciencedirect.com/science/article/pii/ S0921509317305518

[28] G. Bracq, M. Laurent-Brocq, C. Varvenne, L. Perrière, W. Curtin, J.-M. Joubert, I. Guillot, Combining experiments and modeling to explore the solid solution strengthening of high and medium entropy alloys, Acta Materialia 177 (2019) 266-279.

[29] J. Kottke, M. Laurent-Brocq, A. Fareed, D. Gaertner, L. Per- 
rière, Ł. Rogal, S. V. Divinski, G. Wilde, Tracer diffusion in the ni-cocrfemn system: Transition from a dilute solid solution to a high entropy alloy, Scripta Materialia 159 (2019) 94-98.

30] G. Bracq, M. Laurent-Brocq, L. Perrière, R. Pirès, J.-M. Joubert, I. Guillot, The fcc solid solution stability in the co-crfe-mn-ni multi-component system, Acta Materialia 128 (2017) 327 - 336. doi:https ://doi .org/10.1016/j . actamat.2017.02. 017. URL http://www.sciencedirect.com/science/article/pii/ S1359645417301088

[31] M. Laurent-Brocq, L. Perrière, R. Pirès, G. Bracq, T. Rieger, Y. Danard, I. Guillot, Combining tensile tests and nanoindentation to explore the strengthening of high and medium entropys10 alloys, Materialia 7 (2019) 100404.

[32] Y. Zhang, T. T. Zuo, Z. Tang, M. C. Gao, K. A. Dahmen, P. K. Liaw, Z. P. Lu, Microstructures and properties of high-entropy alloys, Progress in Materials Science 61 (2014) 1-93.

[33] G. Henkelman, B. P. Uberuaga, H. Jónsson, A climbing image nudged elastic band method for finding saddle points and minimum energy paths, The Journal of Chemical Physics 113 (22) (2000) 9901-9904. doi:10.1063/1.1329672.

[34] G. Henkelman, H. Jónsson, Improved tangent estimate in the $e_{815}$ nudged elastic band method for finding minimum energy paths and saddle points, The Journal of Chemical Physics 113 (22) (2000) 9978-9985. doi:10.1063/1.1323224.

[35] E. Bitzek, P. Koskinen, F. Gähler, M. Moseler, P. Gumbsch, Structural Relaxation Made Simple, Phys. Rev. Lett. 97 (17) (2006) 170201. doi:10.1103/PhysRevLett.97.170201.

[36] S. Plimpton, Fast parallel algorithms for short-range molecular ${ }^{820}$ dynamics, Tech. Rep. SAND-91-1144, 10176421 (May 1993). doi: 10.2172/10176421.

[37] P. Hirel, Atomsk: A tool for manipulating and converting atomic data files, Computer Physics Communications 197 (2015) 212-219. doi:10.1016/j.cpc.2015.07.012.

[38] A. Stukowski, Visualization and analysis of atomistic simulation data with OVITO-the Open Visualization Tool, Modelling Simul. Mater. Sci. Eng. 18 (1) (2010) 015012. doi: 10.1088/0965-0393/18/1/015012.

[39] K. A. Fichthorn, W. H. Weinberg, Theoretical foundations of dynamical Monte Carlo simulations, The Journal of Chemical Physics 95 (2) (1991) 1090-1096. doi:10.1063/1.461138.

[40] A. Bortz, M. Kalos, J. Lebowitz, A new algorithm for monte carlo simulation of ising spin systems, J. Comp. Phys. 17 (1975) $10-18$.

[41] Diffusion in Solids, Springer Berlin Heidelberg, 2007.

[42] G. E. Murch, Diffusion correlation and isotope effects in highdefect-content solids, Philosophical Magazine A 49 (1) (1984) 21-29. doi: 10.1080/01418618408233425.

775 [43] A. Paul, T. Laurila, V. Vuorinen, S. V. Divinski, Thermodynamics, diffusion and the Kirkendall effect in solids, Springer, 2014.

[44] L. G. Harrison, Influence of dislocations on diffusion kinetics in solids with particular reference to the alkali halides, Trans. Faraday Soc. 57 (1961) 1191-1199. doi:10.1039/TF9615701191.

[45] J. C. Fisher, Calculation of diffusion penetration curves for surface and grain boundary diffusion, Journal of Applied Physics 22 (1) (1951) 74-77. doi:10.1063/1.1699825.

[46] T. Suzuoka, Exact solutions of two ideal cases in grain boundary diffusion problem and the application to sectioning method, Journal of the Physical Society of Japan 19 (6) (1964) 839-851. doi:10.1143/JPSJ.19.839.

[47] H. Mehrer (Ed.), Diffusion in Solid Metals and Alloys, Vol. 26, Springer Berlin Heidelberg, 1990. doi:10.1007/b37801.

[48] A. Vladimirov, V. Kaigorodov, S. Klotsman, I. Trakhtenberg, The volume and intercrystalline diffusion of silver in nickel, Fiz. Met. Metalloved. 45 (5) (1978) 1015-1023.

[49] K. Monma, H. Suto, H. Oikawa, Diffussion of ni63 and cr51 in nickelchromium alloys, J. Jpn Inst. Metals 28 (1964) 188-192.

50] H. Bakker, J. Backus, F. Waals, A curvature in the arrhenius plot for the diffusion of iron in single crystals of nickel in the temperature range from 1200 to $1400 \mathrm{c}$, physica status solidi (b)
45 (2) (1971) 633-638.

[51] M. Bronfin, G. Bulatov, I. Drugova, Self-diffusion of ni in the intermetallic compound ni 3 al and pure ni, Fiz. Met. Metalloved. 40 (2) (1975) 363-366.

[52] K. Maier, H. Mehrer, E. Lessmann, W. Schüle, Self-diffusion in nickel at low temperatures, Physica status solidi (b) 78 (2) (1976) 689-698

[53] G. Murch, The haven ratio in fast ionic conductors, Solid State Ionics 7 (3) (1982) 177-198. doi:10.1016/0167-2738(82) 90050-9.

[54] D. Frenkel, B. Smit, Understanding Molecular Simulation: From Algorithms to Applications, 2nd Edition, no. 1 in Computational Science Series, Academic Press, San Diego, 2002.

\section{Appendix A. Appendix}

Fig. A.9 shows the tracer correlation factor obtained from the conventional random alloy model after $10^{12}$ steps compared to the correlation factor determined with the new KMC code using a constant vacancy migration energy $\left(10^{6}\right.$ and $10^{8}$ steps). Three different set jump rates are used as input $1-100-100-10000-10000,10000-1-1-$ $100-100,1-10-10-1000-1000$, for species A through E respectively. We find significant deviations between both codes after $10^{6}$ steps but overall great agreement after $10^{8}$ steps. 
Table A.4: Element concentrations (in at.\%) as determined by EDS analyses of the homogenized rods which are used radiotracer diffusion experiments.

\begin{tabular}{|c|c|c|c|c|c|}
\hline Sample & Co & Cr & Fe & Mn & Ni \\
\hline $\mathrm{Co}_{10} \mathrm{Cr}_{10} \mathrm{Fe}_{10} \mathrm{Mn}_{10} \mathrm{Ni}_{60}$ & $10.13 \pm 0.12$ & $10.30 \pm 0.10$ & $10.18 \pm 0.12$ & $10.38 \pm 0.16$ & $59.01 \pm 0.22$ \\
\hline $\mathrm{Co}_{2} \mathrm{Cr}_{2} \mathrm{Fe}_{2} \mathrm{Mn}_{2} \mathrm{Ni}_{92}$ & $2.07 \pm 0.09$ & $2.10 \pm 0.08$ & $2.11 \pm 0.07$ & $2.07 \pm 0.11$ & $91.66 \pm 0.16$ \\
\hline
\end{tabular}

a)

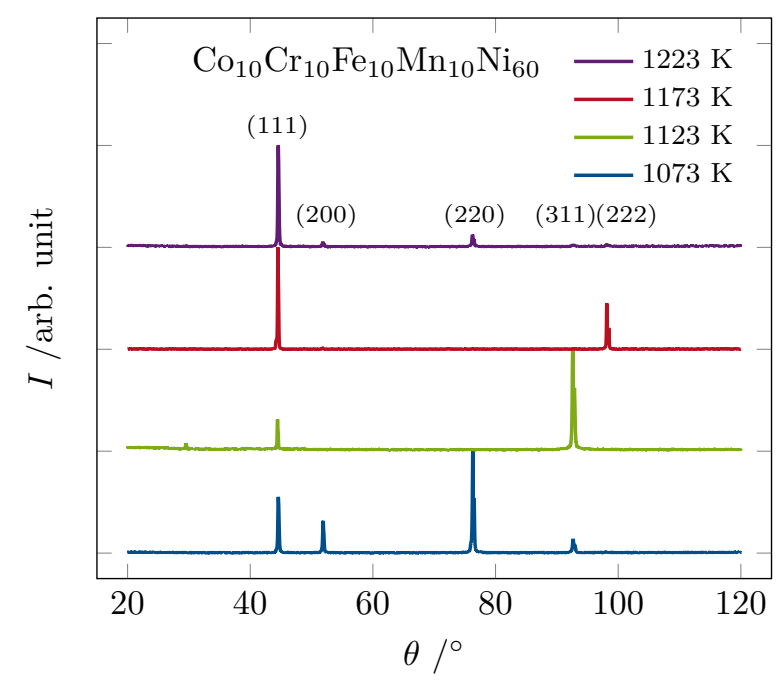

b)

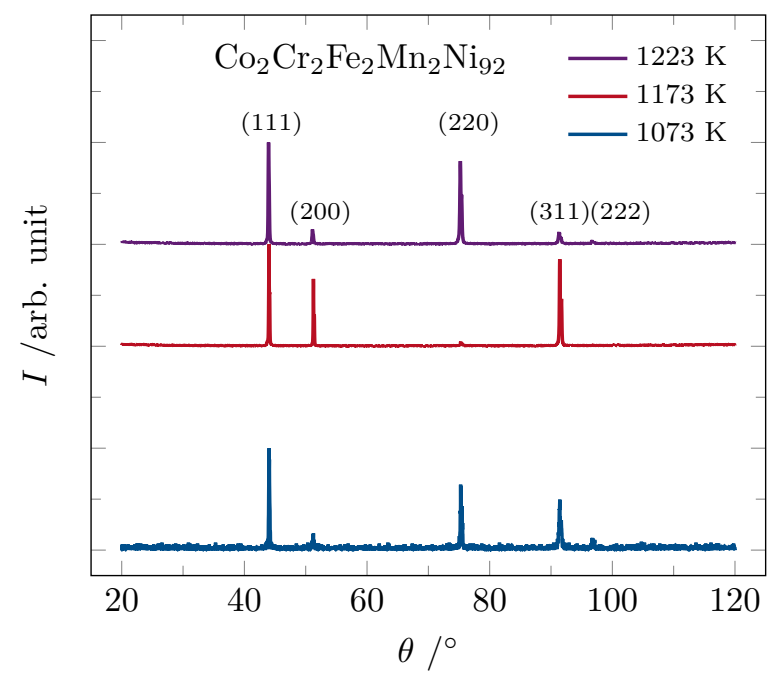

Figure A.8: X-ray diffraction patterns of (a)) $\mathrm{Co}_{10} \mathrm{Cr}_{10} \mathrm{Fe}_{10} \mathrm{Mn}_{10} \mathrm{Ni}_{60}$ and (b)) $\mathrm{Co}_{2} \mathrm{Cr}_{2} \mathrm{Fe}_{2} \mathrm{Mn}_{2} \mathrm{Ni}_{92}$ of the pre-annealed states. All patterns prove the formation of a single face-centred cubic phase. The samples were measured using a Siemens D5000 in $2 \theta$-setup with a Cu-K $\mathrm{K}_{\alpha}$ source. The measurement itself was taken from 20 to $120^{\circ}$ with an accumulation for $10 \mathrm{~s}$ for each $0.02^{\circ}$. The intensities have been normalized for a better comparison. 

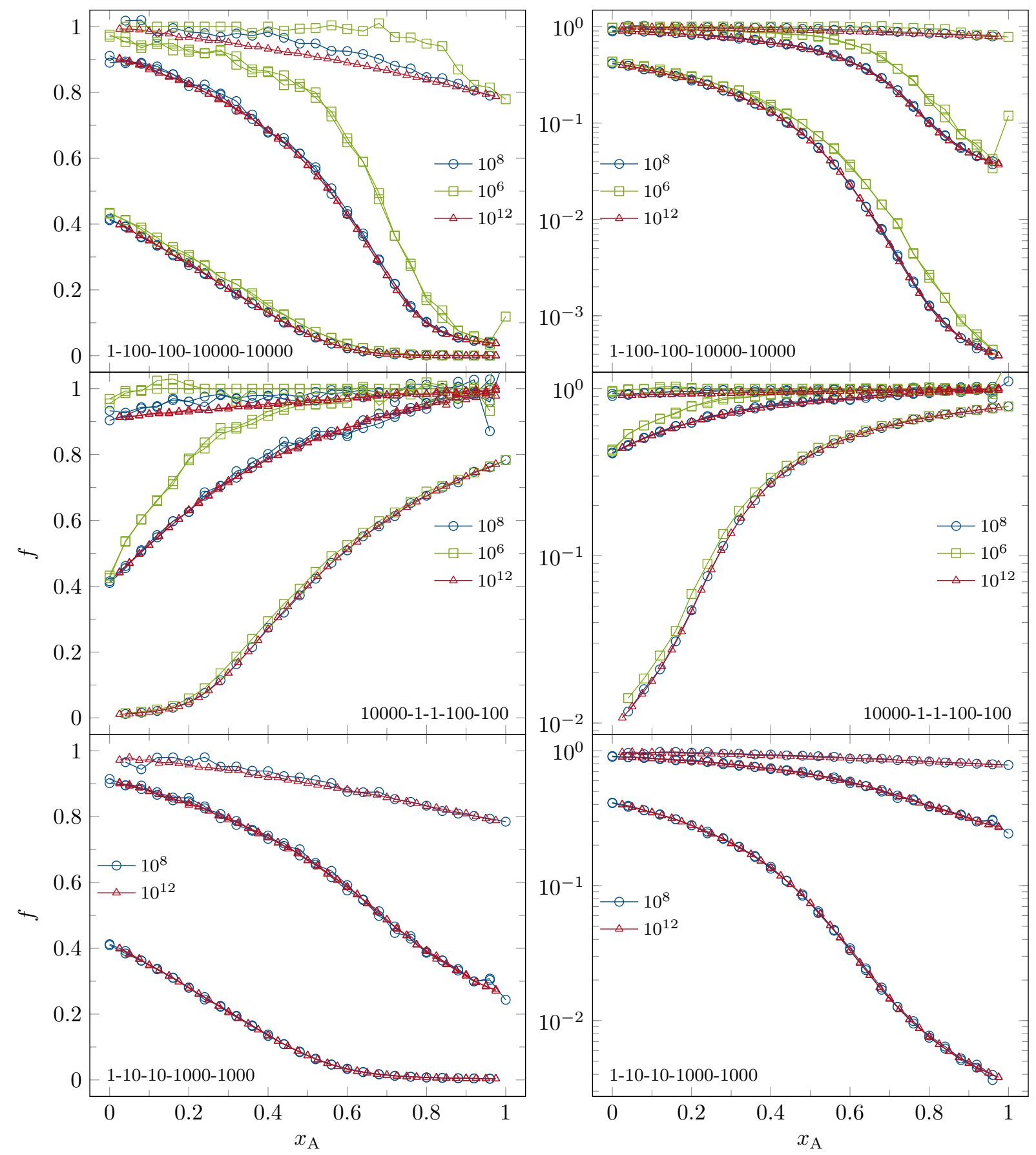

Figure A.9: Comparison of the correlation factor $f$ using the KMC code developed for this publication compared to a conventional random alloy model implementation. The legend entry denotes the number of MC steps taken, $10^{12}$ marks the conventional implementation of the random alloy model, while $10^{6}$ and $10^{8}$ data points were obtained from the new KMC implementation. The graphs on the left side show the deviations on a linear scale and the data on the right side are the same results plotted against a logarithmic scale. 


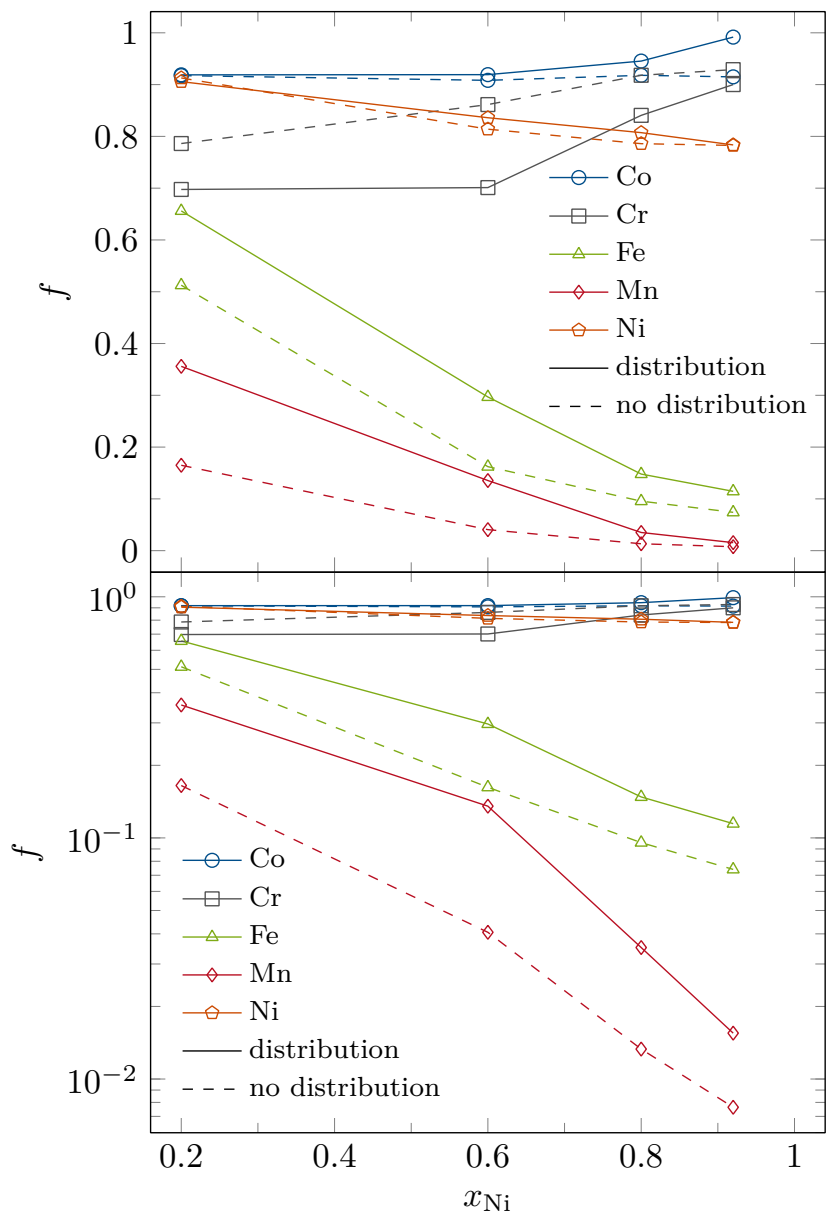

Figure A.10: Correlation factors obtained from the KMC simulation after $10^{8}$ steps. Solid lines represent KMC results where the migration energy barrier are taken with a finite width (Tab. 3). Dashed lines show $f$ with the a constant mean activation barrier but no distribution. This data corresponds to the random alloy model. In all cases $f$ was sampled at $1123 \mathrm{~K}$. 